\title{
LOS EVENTOS DISTINTIVOS EN GRANDES DESTINOS DEL TURISMO CULTURAL. EL CASO DEL AÑO GRECO EN TOLEDO (ESPAÑA)*
}

\author{
Luis Alfonso Escudero Gómez. \\ Universidad de Castilla-La Mancha \\ https://orcid.org/0000-0002-7954-4064
}

\section{RESUMEN}

El turismo cultural se ha expandido en las últimas décadas. Los destinos turísticos son parte de un mercado altamente competitivo. El patrimonio se ha convertido en un valor económico. Se ha producido la generalización de su comercialización a través de distintos productos turísticos. Es el caso de los eventos culturales con vocación turística. Entre ellos, destacan los eventos distintivos (hallmark events). Son acontecimientos excepcionales. Se desarrollan para mejorar el atractivo y la rentabilidad de un destino. Las efemérides son una oportunidad para organizarlos mediante la celebración de conmemoraciones. En este artículo se analizan los eventos distintivos en grandes destinos del turismo cultural. Con este fin, se realiza un estudio de caso a través del análisis post evento del IV Centenario de la muerte del Greco en la ciudad de Toledo. La metodología empleada consta de la revisión literaria, de la observación directa, del estudio de fuentes y de una encuesta entre visitantes y residentes. Los resultados demostrarán el gran alcance económico y turístico del evento. Sin embargo,

Fecha de recepción: 2 de marzo de 2018

Fecha de aceptación: 12 de noviembre de 2018

Departamento de Geografía y Ordenación del Territorio. Universidad de Castilla-La Mancha. Facultad de Humanidades. Plaza de Padilla 4. 45071 TOLEDO (España). E-mail: LuisAlfonso.Escudero@uclm.es

* Agradecimientos: El autor agradece a los evaluadores anónimos del artículo sus comentarios, así como los cambios y mejoras propuestos, quedando los posibles errores finales a cargo exclusivamente del investigador. Da las gracias a sus alumnos de la asignatura Turismo y Patrimonio del cuarto curso del Grado de Humanidades y Patrimonio de la Facultad de Humanidades de Toledo, año 2014/15, por su colaboración en la realización de la encuesta.

Financiación: Este articulo forma parte del proyecto de investigación Dinámicas de urbanización y políticas urbanísticas en ciudades medias interiores. De expansión y dispersión a reformulación: ¿Hacia un urbanismo más ¿urbano??, subvencionado por el Programa Estatal de Investigación, Desarrollo e Innovación Orientada a los Retos de la Sociedad, Convocatoria 2015, Modalidad 1: «Proyectos de I+D+i» del Ministerio de Economía y Competitividad con referencia CSO2015-63970-R (MINECO/FEDER). 
entre los visitantes, el Año Greco fue un motivo secundario para acudir al destino. En la comunidad anfitriona, el $40 \%$ de los residentes no participaron en el evento.

Palabras clave: Geografía del Turismo; turismo cultural; patrimonio; turismo de eventos; eventos distintivos; España; Toledo.

\title{
The hallmark events in great cultural touristic destinations. The case of Greco's year in Toledo, Spain
}

\begin{abstract}
Cultural tourism has really taken off in the last decade touristic destinies are now part of a highly competitive market. The heritage has turned into an economic asset. Generalization of its trading is now in place through various touristic products. This is the case of cultural events focusing tourism. Among them stand out hallmark events. These are exceptional events. They take place in order to improve the attractiveness and cost effectiveness of a touristic destination. These occurrences are an opportunity to organize them through remembrance services. In this article we go through hallmark events in main cultural touristic destinies. That's the reason why we carry out a study in order to analyze later events after Greco's death in the city of Toledo, the IV centenary of his death. The approach used consists of a literary revision, direct observation analyze sources of information and a poll amongst visitors and inhabitants. The results will show the great economic and touristic scope of the event. However among visitors, Greco's year was a secondary reason to attend the venue.

In the host community $40 \%$ of the inhabitants didn't take part in the event.
\end{abstract}

Keywords: Tourism Geography; cultural tourism; heritage; event tourism; hallmark events; Spain; Toledo.

«En la actualidad cultura y turismo parecen darse la mano más que nunca» Sánchez y Guitart (2017) «El año en el que El Greco batió todos los récords» García (2014)

\section{INTRODUCCIÓN}

En las últimas décadas, es evidente el intenso desarrollo que ha tenido el turismo, no solo en el aumento de los flujos turísticos sino también en la búsqueda permanente de nuevas modalidades turísticas. Ha habido una expansión de la oferta turística que se procesa a través de la formulación de nuevos productos. Al mismo tiempo, ha tenido lugar un notable interés y preocupación por la conservación y valorización turística de bienes y lugares patrimoniales (Troncoso y Almirón, 2011).

El turismo cultural ha cobrado una gran importancia, pasando de ser una actividad de la élite minoritaria a ser algo frecuente y cotidiano (Bedate, Herrero y Sanz, 2004: 102). Su desarrollo tiene lugar principalmente en los centros históricos de las ciudades (Ashworth y Tunbridge, 2000). Se produce una simbiosis entre cultura, patrimonio y turismo (Jansen- 
Verbeke y Lievois, 1999: 87). De esta forma, el turismo cultural es visto como el segmento de mayor crecimiento en el mercado turístico europeo (Richards, 1996: 87) o en cualquier lado (Zeppel y Hall, 1992). En España, las ciudades históricas empiezan a elaborar una política turística propia a lo largo de los años noventa del siglo XX, en un periodo que coincide con su redescubrimiento como destinos turísticos (De la Calle y García, 2016: 692). Las ciudades o conjuntos históricos declarados Patrimonio de la Humanidad de la Unesco, como el estudio de caso, Toledo, constituyen un valor añadido para garantizar la existencia de un rico patrimonio histórico y cultural que satisface las demandas de los turistas culturales (Cordente et al., 2011: 84).

Sin embargo, desde hace tiempo, existe bastante convencimiento de las limitaciones que tiene la visita turística patrimonial de formato más clásico. La atracción cultural funciona como marcador generador del viaje (Leiper, 1990). Un creciente número de ciudades y regiones están basando el desarrollo del turismo en la promoción del patrimonio cultural y la cantidad de atracciones culturales está creciendo rápidamente (Richards, 2005: 10). Hoy la oferta ha aumentado tanto que da lugar a una presión competitiva entre los destinos (Richards, 2001: 10). Este hecho justifica una opción generalizada por acometer estrategias de diversificación (De la Calle y García, 2016: 699). Los turistas están cada vez más interesados en los aspectos culturales y eligen un destino que también ofrezca experiencias culturales emocionantes (Richards y Bonink, 1995). Se trataría de aprovechar los valores intangibles relacionados con la cultura, los cuales pueden proceder de diversas temáticas como la historia, las artes o la gastronomía (Muñiz y Cervantes, 2010: 144). Estos recursos patrimoniales están siendo transformados en productos turísticos con una renovada apreciación de los eventos culturales (Jansen-Verbeke y Lievois, 1999: 82-83). Los acontecimientos culturales han pasado de ser para los residentes a ser focos de atracción de visitantes (Askins y Pain, 2011). Juegan un importante papel en la creación de imagen, en el posicionamiento y en la promoción de los destinos turísticos (Pine y Gilmore, 1999 y Amara, 2017).

El turismo de eventos supone un desarrollo de los destinos. Tiene capacidad para generar crecimiento local y atraer a los turistas (González y Morales, 2017: 340). Los eventos son un importante motivador del turismo y una figura prominente en los planes de desarrollo y mercadotecnia de muchos destinos (Getz, 2008: 404). Pueden generar nuevos productos en un relativo corto espacio de tiempo, dando lugar a visitas repetidas y mayores gastos (Richards 2005: 69). Sirven para distinguir una ciudad o una región de sus competidores y pueden renovar o animar un destino turístico (Richards, 1993). Las ciudades utilizan cada vez más los eventos culturales para mejorar su imagen, estimular el desarrollo urbano y atraer visitantes e inversión (Richard y Wilson, 2004: 1931). Hay un creciente aumento de eventos culturales y turísticos celebrados en los últimos años (González y Morales, 2017: 340). La agenda de los eventos culturales está en explosión, dentro de un proceso de renacimiento cultural y de búsqueda de nuevos nichos turísticos de mercado (Jansen-Verbeke y Lievois, 1999: 88). Cada año una gran cantidad de eventos de diferente naturaleza motiva a los turistas a visitar las ciudades que los alojan (Piva et al., 2017: 100). Se trataría de eventos donde la fuerza impulsora es claramente el turismo (Getz, 2008: 422). La proliferación de los eventos, cuya dimensión simbólica es potenciada y ennoblecida por la cultura, se convierte hoy en materia 
prima para la mercadotecnia urbana (Fessler y Berenstein, 2006). Por lo tanto, cada vez más destinos intentan aprovechar el potencial de los eventos en la implementación de diversos objetivos económicos y turísticos (Oklobdzija, 2015).

Debido a esta profusión de eventos es importante establecer tipologías de los mismos. Resulta muy útil la diseñada por Getz (2005) en función de la demanda y del valor ${ }^{1}$. Distingue entre mega-eventos, con alta demanda y alto valor; eventos distintivos o de sello (hallmark), también con alta demanda y valor; eventos regionales, con una demanda turística media; y eventos locales, con baja demanda y/o bajo valor. Los mega-eventos hacen referencia a acontecimientos globales como los deportivos y las exposiciones universales. En el ámbito de los eventos culturales con valor turístico destacarían los eventos distintivos (hallmark event) que Ritchie (1984: 2) define como «eventos importantes de una sola vez o recurrentes de duración limitada, desarrollados principalmente para mejorar la conciencia, el atractivo y la rentabilidad de un destino turístico».

La ventaja importante que tienen los sitios patrimoniales es la presencia de capital cultural real sedimentado (Zukin, 1991). Este patrimonio puede dar lugar a la creación de nuevos productos como son los eventos culturales. Son de especial interés los de carácter distintivo, con marca o sello (hallmark). Richards (2017:12) señala que se necesitan más análisis e investigaciones para examinar los diferentes tipos de eventos, el perfil del visitante y el comportamiento. En este artículo se pretende aportar un estudio sobre los eventos culturales distintivos celebrados en destinos turísticos culturales consolidados. La tendencia académica hoy es seguir investigando estudios de caso, quizá porque cada territorio cuenta con sus propias características y no siempre se pueden replicar las mismas metodologías (Pulido y Ruiz, 2017: 403). Su y Wall (2013) concluyen que es necesario articular más estudios de casos, con mayor detalle, con conceptos claros y marcos teóricos, en una diversidad de sitios para conducir a la comprensión de la relación turismo y patrimonio. Getz (1989 y 1991) argumenta que hay una necesidad de informes de estudios de casos de los eventos y sus impactos. Poseen múltiples dimensiones e implican diferentes consecuencias, no siempre positivas (Hollinshead, Kuon y Alajmi, 2015). En la investigación sobre el turismo de eventos, Getz (2008: 417) señala la importancia de las evaluaciones posteriores a su celebración. Se escoge esta opción en el presente artículo, analizando un evento turístico distintivo en un destino cultural consolidado tras su finalización. Se considera que el enfoque de estudio de caso es una metodología cualificada para una comprensión profunda sobre los eventos distintivos en destinos turísticos culturales.

El núcleo estudiado en el presente artículo es un valioso ejemplo. Toledo, ciudad histórica y patrimonial, es uno de los principales destinos de turismo cultural de España, junto con Granada y la Alhambra y Santiago de Compostela y su Camino (Escudero, 2018). Sin embargo, el modelo turístico de Toledo es de tipo maduro con síntomas a inicios del actual siglo de cierto agotamiento (Troitiño, 2005: 417). Por esta razón, esta ciudad viene celebrando acontecimientos que tienen una orientación cultural, aprovechando conmemoraciones de significado histórico como el V Centenario del nacimiento de Carlos V en

1 Las medidas de valor de los eventos serían el potencial de crecimiento, la cuota de mercado, la calidad, la mejora de la imagen, el apoyo de la comunidad, el valor ambiental, los beneficios económicos, la sostenibilidad y la adecuación (Getz, 2005). 
$2000^{2}$ o el IV Centenario de la publicación del Quijote en 2005. El fin es incentivar la actividad turística en Toledo creando nuevos productos. En el año 2014, con el motivo de la conmemoración del IV Centenario de la muerte del Greco, se realizó una fuerte inversión en su celebración. Se trataba de una clara apuesta para promocionar y desarrollar el turismo en la ciudad a través del denominado Año Greco.

Tenemos que tener en cuenta que existen múltiples enfoques sobre los impactos de la celebración de eventos y esto impide un acercamiento holístico (González y Morales, 2017: 343). No obstante, se pretende comenzar con una visión general del evento. Así, se tiene en cuenta en primer lugar el hecho de que el turismo de eventos está impulsado principalmente por el objetivo de los beneficios económicos. Las primeras preguntas de investigación van en este sentido: ¿fue el Año Greco un impulso real de la actividad turística en Toledo? ¿Aumentó el número de visitantes? ¿Generó ingresos? Por otro lado, también se deben examinar los resultados e impactos a nivel social, y también en términos de cambio cultural (Getz, 2008: 419). Surgen así nuevas preguntas: ¿los visitantes de Toledo venían por motivos culturales? En caso de respuesta afirmativa, ¿es el evento la razón por la cual han optado por el destino? De hecho, ¿sabían que se celebraba? Finalmente, ¿los visitantes de la ciudad participan en las actividades culturales del evento?

Al mismo tiempo, la percepción de los residentes y sus actitudes hacia los eventos es otro importante tema de investigación en estudios de casos (Boyko, 2008; Jackson, 2008 y Oom do Valle, Mendes y Guerreiro, 2012). Se ha señalado que los eventos distintivos no pueden existir independientemente de su comunidad anfitriona (Getz, 2008: 408), pero ¿los eventos culturales distintivos como el Año Greco transcienden a la sociedad local? En caso de respuesta positiva ¿cómo? ¿Mediante un sentimiento de identidad cultural exclusivamente o también a través de la participación activa de los residentes en los actos programados? ¿Es cierto que, como afirma Light (1996), los eventos tienen un atractivo especial para la gente del sitio? Dado que grandes minorías de la población local no ven los espacios patrimoniales como lugares para pasar su tiempo libre (Light, 1996: 188), ¿son los eventos culturales una motivación para que la comunidad anfitriona visite sus sitios patrimoniales?

Con este artículo se pretende contribuir a una mayor comprensión de los impactos de los eventos distintivos en destinos turísticos culturales mediante las respuestas a todas estas preguntas de investigación. Ese es el objetivo. La estructura del artículo comienza con esta introducción. A continuación, se establece el marco teórico con una breve revisión literaria y analizando los eventos culturales y su valor turístico. Después, se detalla la metodología empleada. Posteriormente, se presentan los resultados con el análisis post evento del estudio de caso. Finalmente, se cierra el trabajo con las conclusiones. Los hallazgos de este estudio se ubican en el contexto de otros análisis de eventos en sitios patrimoniales. Los resultados pueden ayudar a dar forma a la evaluación, planificación y política para eventos.

2 El acto principal fue la celebración de la exposición Carolus en el Museo de Santa Cruz que atrajo a 220.000 visitantes (Mínguez, 2013: 19). 


\section{MARCO TEÓRICO}

\subsection{Breve revisión literaria}

El turismo patrimonial se ha convertido en uno de los temas más investigados en el campo de los estudios de turismo (Timothy y Boyd, 2006: 2). De una manera general, Timothy y Boyd (2003) han profundizado sobre el turismo patrimonial; Herbert (1995) sobre la relación entre patrimonio, turismo y sociedad; Chambers (1997) acerca del turismo y la cultura, Zeppel y Hall (1991) y Timothy (2011) sobre el patrimonio cultural y el turismo y Ashworth (1993) acerca del patrimonio, el turismo y los lugares. Richards (2005) ha estudiado el alcance y la importancia del turismo cultural y Timothy y Boyd (2006) se han centrado en sus perspectivas actuales. De hecho, la bibliografía del turismo cultural es extremadamente amplia. Las obras citadas serían tan solo una primera aproximación.

El estudio de los eventos ha existido durante mucho tiempo dentro de varias disciplinas, como la Antropología, la Geografía o las Ciencias Económicas (Getz, 2008: 405). A partir de la década de los 1980 se expande la investigación sobre el turismo de eventos (Getz, 2008: 409). Al tiempo que crecía considerablemente el número de eventos turísticos también lo hacía el interés académico hacia su estudio (Light, 1996: 183). Actualmente, la literatura sobre eventos ha crecido más allá de la capacidad de cualquier persona de leerlo todo (Getz, 2008: 410). Ya a final del siglo pasado aparecen artículos sobre análisis bibliográficos de los estudios del tema (Formica, 1998). Getz en 2007 publica un libro donde analiza la teoría, la investigación y la política de los eventos planificados. La última edición de esta monografía es de 2016 con la coautoría de Page (Getz y Page, 2016a). Getz en 2008 también establece la definición, evolución e investigación del turismo de eventos. En 2013 amplia este trabajo mediante un libro acerca del concepto de turismo de eventos y el análisis de su investigación y de diferentes estudios de casos internacionales (Getz, 2013). El progreso y perspectivas para la investigación de eventos ha sido establecida en el presente por Mair y Whitford (2013) y Getz y Page (2016b).

El valor de los eventos es tratado de manera amplia y general en la reciente obra editada por Lundberg (2017). Anteriormente, Burgan y Mules (2001) estudian los impactos económicos del turismo de eventos a través de la relación coste-beneficio. Richards y Palmer (2010) analizan como los eventos ofrecen potencial para lograr resultados económicos, sociales, culturales y ambientales dentro de estrategias de revitalización urbana. Oklobdzija (2015) se ocupa del papel de los eventos en el desarrollo del turismo. Getz (1997 y 2005) ha publicado obras de referencia sobre la gestión de eventos, en especial, los de valor turístico. Backman (2017) analiza cuáles son los enfoques actuales y futuros de la investigación en la gestión de eventos.

La cuestión específica de los eventos distintivos, de marca o sello (hallmark events) es tratada ya por Ritchie y Beliveau (1974) y Ritchie (1984). Hall (1989) los definía y los analizaba como eventos turísticos singulares. Posteriormente, publicaba una obra sobre los impactos, la gestión y la planificación de estos particulares acontecimientos (Hall, 1992). En la obra editada por Syme et al. (1989) se trata sobre la planificación y 
la evaluación de los eventos distintivos. Su alcance y las características de su audiencia son tratados por Roslow, Nicholls y Laskey (1992). Boyle (1997), analizando un estudio de caso del papel de Glasgow como capital europea de la cultura en 1990, concluye que hay concepciones notablemente empobrecidas de los antecedentes materiales y culturales dentro de los cuales se organizan los eventos distintivos. Boyko (2008) analizó las percepciones de los residentes sobre un evento distintivo, la capitalidad europea cultural de Brujas en 2002. Todd, Leask y Ensor (2017) han estudiado los papeles de los actores implicados en la gestión de los eventos distintivos. Chirieleison y Scrucca (2017) se ocupan de cuestiones relativas al transporte y la sostenibilidad en estos acontecimientos singulares. Beek y Go (2017) investigan sobre su legado en destinos turísticos emergentes y Nordvall y Heldt (2017) estudian el caso de un evento distintivo fracasado en la ciudad sueca de Borlänge.

En el ámbito español, los aspectos más generales de la relación entre el turismo y el patrimonio han sido tratados ya en diferentes manuales acerca del turismo cultural (Pulido, 2013), su mercadotecnia (Recuero, Blasco y García de Madariaga, 2016) y la gestión turística del patrimonio cultural (Martos, 2016). De una manera más específica, De la Calle y García (1988) analizan el patrimonio cultural como recurso turístico en las ciudades históricas. En esas ciudades, Lara de Vicente y López (2004) identifican el turismo como motor de desarrollo económico. Herrero y Gómez (2017) han estudiado los recursos culturales como factor de atracción del turismo. De la Calle (2002) trata a la ciudad histórica como destino turístico. Además, se han publicado diferentes estudios de casos basados en ciudades patrimoniales como Córdoba (López-Guzmán, Pérez y Muñoz, 2018), Cuenca (García Marchante, 2011), Granada (Murillo, Romaní y Suñirach, 2008) o Salamanca (Cavaillès et al., 2016), por citar algunos ejemplos. La bibliografía sobre el turismo cultural en la literatura española es también ya muy extensa.

En relación con la cuestión del turismo de eventos, es una temática de creciente interés entre los académicos españoles. González y Morales (2009) estudian en una monografía el turismo urbano y la producción de eventos. La revista Pasos ha publicado un número especial, coordinado por Richards y Ruiz (2017), para analizar la experiencia turística de festivales y eventos culturales. González y Morales (2017) han publicado recientemente un artículo sobre el impacto cultural y social de los eventos celebrados en destinos turísticos. Su análisis se realiza desde la percepción de sus organizadores. Devesa, Herrero y Sanz (2009) han realizado una investigación económica de las demandas de los festivales culturales. Martínez y Campillo (2018) han tratado los eventos como una herramienta clave en las estrategias de comunicación de marcas turísticas. Troitiño, García y De la Calle (2003) analizan los rasgos específicos de los visitantes de eventos turísticos-culturales en las ciudades históricas españolas. Mínguez (2013) estudia las actividades culturales en destinos turísticos patrimoniales españoles. Incluye en su artículo los casos de Ávila, Segovia y el propio Toledo. Rodríguez (2015) se ha ocupado del análisis de un tipo particular de eventos culturales, los centenarios, y dentro de la comunidad autónoma de Castilla-La Mancha. Para esta autora, serían eventos dinamizadores de la cultura, el arte y la actividad turística. Laguna (2005) estudia el impacto turístico y económico de los eventos culturales en las ciudades históricas a través del estudio de caso de la exposición Edades del Hombre en Segovia. Martos (2013) 
analiza el papel del turismo de eventos en el desarrollo urbano a través del caso del megaevento Expo Zaragoza 2008. Novello et al. (2014) estudian el caso del año santo jubilar compostelano o Xacobeo en Santiago de Compostela y cómo se ha transformado de un recurso a un evento turístico global. Salom y Pitarch (2017) analizan el impacto en el turismo de los megaproyectos en Valencia, incluyendo el estudio de la celebración de grandes eventos deportivos en esa ciudad.

Con respecto a los trabajos académicos previos sobre el turismo cultural en Toledo. Troitiño ya publicaba una perspectiva general en 1997. Al año siguiente, es destacable el artículo de Troitiño et al. (1998). Este trabajo proporcionaba una explicación detallada de los problemas causados por el turismo en Toledo en ese momento. Relacionaban estos problemas con la realidad de la ciudad y con la planificación urbana, proponiendo medidas para planificar mejor el turismo cultural. El estudio de Toledo como destino patrimonial, sus características y problemáticas ocupará un capítulo de libro realizado por Troitiño y Troitiño en 2009. Casi una década después, Escudero (2018) analiza de un modo holístico las realidades y problemas de Toledo como destino turístico cultural.

Otros investigadores españoles también se interesan en el caso de Toledo como destino turístico patrimonial. Se citan brevemente por orden cronológico algunas referencias. Brandis y Del Río (1998) estudian el impacto del turismo en el medio ambiente urbano a través de tres casos, uno de ellos, Toledo (con Ávila y Salamanca). Zárate (2000) describe la ciudad como gran destino turístico a raíz de su condición como Patrimonio de la Humanidad. Ruiz-Ayúcar (2002) detalla el Plan de Excelencia Turística de Toledo. Troitiño (2005) recapitula sobre la oferta patrimonial y cultural de la ciudad y analiza su funcionalidad turística. López (2005) propone un desarrollo sostenible del turismo de Toledo basado en la conservación patrimonial y paisajística y proponiendo un control del crecimiento de la actividad turística. García Álvarez (2007) analiza los orígenes del turismo en la ciudad, las primeras políticas turísticas y la creación de una imagen patrimonial e histórica. Desde el ámbito de la Economía, Díaz et al. (2007) investigan la demanda turística de Toledo, segmentándola en perfiles de mercado. El geógrafo Zárate (2008) propone estrategias para la dinamización turística en la ciudad. Troitiño (2010) analiza la funcionalidad turística de los recursos monumentales de las ciudades Patrimonio de la Humanidad de España escogiendo a Toledo como estudio de caso, junto a Ávila, Cuenca y Segovia. García Martínez (2011) estudia la interpretación romántica de Toledo a través de los relatos de viajeros entre 1830 y 1870 y cómo la utilización de estas imágenes se inserta en su modelo actual de turismo urbano. García Martín (2013) realiza una investigación muy específica sobre el turismo cultural de Toledo. En ella, describe la segmentación del mercado turístico basada en el uso del tiempo. Vázquez y Martínez (2016) estudian el impacto del tren de alta velocidad en el desarrollo turístico de la ciudad. Zárate (2016) analiza la cuestión de los paisajes culturales de Toledo y su relación con el turismo cultural y las dinámicas urbanas. Pillet (2017) estudia el turismo urbano de Toledo y lo caracteriza como el primer destino turístico de Castilla-La Mancha. Finalmente, Martín (2017) realiza una tesis doctoral sobre la difusión del valor cultural en las ciudades Patrimonio Mundial de la Península Ibérica con Toledo como estudio de caso. En ella, se recogen diferentes aspectos relacionados con la promoción turística de la ciudad. 


\subsection{Los eventos culturales, un valor turístico}

El turismo cultural es un concepto problemático (Richards, 2005: 21), de difícil definición y en constante cambio (Richards, 2005: 25). Algunos autores prefieren hablar específicamente de un turismo patrimonial (Timothy y Boyd, 2003), aunque también este término es de difícil definición (Garrod y Fyall, 2001). De una manera conceptual, Richards (2005: 24) define el turismo cultural como el movimiento de personas a atracciones culturales fuera de su lugar de residencia normal, con la intención de reunir nueva información y experiencias para satisfacer sus necesidades culturales. Sin embargo, como en otras tipologías del turismo, la mayoría de los turistas culturales simplemente desean una experiencia vacacional entretenida, agradable y memorable (Timothy y Boyd, 2006: 5).

La comercialización de la nostalgia, de la autenticidad (Waitt, 2000 y Lovell y Bull, 2017), del aprendizaje y del entretenimiento con la utilización de recursos culturales y patrimoniales ha sido utilizada para activar el turismo como un estímulo para la economía urbana y un valor agregado a la vida de las ciudades. En este contexto, el patrimonio cultural es un capital porque puede proporcionar un flujo de productos y generar recursos beneficiosos (Throsby, 2011). El patrimonio aparece cada vez más como atractivo para la práctica turística. Choay (2007) califica este hecho como una «inflación patrimonial», en la cual ha habido un incremento tipológico de la oferta turística patrimonial donde cada vez más nuevos tipos de bienes tienen un uso turístico; un aumento cronológico, donde bienes de un pasado cada vez más próximo al presente se incorporan a la actividad turística; y una expansión geográfica, donde se incluyen cada vez nuevos destinos turísticos.

Los acontecimientos se han convertido, a su vez, en un medio importante para atraer a los turistas y ofrecerles productos innovadores (Richards, 2001: 5). En contraste con las atracciones turísticas permanentes, los eventos son ocurrencias temporales, generalmente con un tema particular, cuyo objetivo es atraer personas (Light, 1996: 183). Gran parte del atractivo de los eventos es que nunca son lo mismo y tienes que estar ahí para disfrutar plenamente de la experiencia única, si te lo pierdes, es una oportunidad extraviada (Getz, 2008: 404). Las razones específicas de un evento turístico están ligadas a su novedad o unicidad. Este hecho da lugar a que mucha gente encuentre una motivación intrínseca para viajar a los eventos (Getz, 2008:416). Contribuyen a la satisfacción general de sus visitantes (Mehmetoglu y Engen, 2011). Los eventos motivan el viaje en el territorio de origen del turista (Leiper, 1990). Pueden ser usados para extender la temporada turística, celebrándolos al principio o al final de la misma, o se pueden emplear para ampliar la demanda durante la temporada (Light, 1996: 183).

Además, los eventos sirven como un catalizador para fomentar una imagen positiva, contribuyen a la mercadotecnia del destino turístico y animan áreas o atracciones específicas (Getz, 2008: 406). Por ello, se han convertido en un componente importante dentro de las estrategias de la marca de destino de un lugar en el contexto actual del posfordismo, la regeneración urbana y el City Branding (Tranquilli, 2013). Los territorios utilizan cada vez más eventos y festivales culturales para mejorar su imagen e impulsar el desarrollo del turismo (Piva et al., 2017: 99). Dan realce y notoriedad a los lugares en los que se realizan debido a su propia calidad artística, religiosa, patrimonial, etc. Propician un incremento de flujos de visitantes interesados en disfrutar estos eventos en el mismo sitio en el que tienen 
lugar (Richards y Ruiz, 2017: 5). Generan así una demanda inducida para los destinos turísticos (Mossberg, 2000). A través del desarrollo de eventos icónicos y distintivos los propios destinos turísticos pueden influir directamente en el proceso (Getz, 2008: 416). Por esta razón, los organismos encargados de promover el turismo en un destino, o DMOs ${ }^{3}$, tienden a ser agencias promotoras del turismo de eventos (Getz, 2008:406). Normalmente, en su organización existe una red suave o informal de actores interesados, dominada por un núcleo de agencias gubernamentales influyentes (Stokes, 2004). De este modo, estos acontecimientos se han producido y promovido cada vez más por razones estratégicas, siendo la principal el desarrollo económico (Getz, 2008: 422).

Así, el discurso sobre los eventos de valor turístico ha estado dominando por las perspectivas turísticas y económicas (Getz, 2008: 404). El turismo puede generar crecimiento económico, inversión y empleo. Los turistas culturales han sido identificados como de alto nivel y alto gasto $\mathrm{y}$, por lo tanto, como un segmento de mercado principal para generar beneficios económicos para un destino (Gratton, 2005: 65). Esta demanda es un factor de desarrollo económico y, por esta razón, se invierten recursos importantes esperando la obtención de beneficios a través del turismo cultural (Getz y Page, 2016a). Aunque la enormidad del impacto económico del turismo patrimonial no puede ser exagerada (Timothy y Boyd, 2006: 4), sí se ha calificado como un gran negocio (Timothy, 2011: 15). Los eventos especiales son una de las fuentes de ingresos más comunes en la actualidad para sitios históricos (Timothy y Boyd, 2003). Pueden atraer visitantes y aumentar las ganancias (Timothy, 2011: 304). Además, suponen un atractivo distinto que alienta las visitas repetidas (Light, 1996: 183). En este sentido, los visitantes de los eventos disfrutan su estancia y se quedan más tiempo que el promedio habitual (Light, 1996: 183). De hecho, contribuyen a la satisfacción y la recreación de los visitantes. El aumentar el entretenimiento puede ser identificado como uno de sus beneficios (Light, 1996: 188).

Los roles e impactos de los eventos en el turismo han sido bien documentados y están incrementando su importancia para la competitividad de los destinos (Getz, 2008: 403). Pueden dar una singularidad cultural de renombre internacional a una ciudad (Muñiz y Cervantes, 2010: 125). Por otro lado, hay una interacción importante entre el contexto y el contenido del evento para influir en la naturaleza de su experiencia (Richards, 2017:12). Convocatorias como los centenarios son eventos de gran difusión a nivel internacional cuando el personaje o la circunstancia que los suscita es de calado y reconocimiento mundial (Rodríguez, 2015: 69). Los eventos culturales acentúan la visibilidad del territorio y de su patrimonio, aumentan su capacidad de atracción de turistas y excursionistas y refuerzan la autoestima de los espacios en los que se desarrollan (Silva y Fernández, 2008: 85). Cavaillès et al. (2016: 38) afirman que, por ejemplo, en Salamanca la programación sucesiva de acontecimientos culturales ha reforzado la reputación patrimonial de la ciudad, ha mantenido su visibilidad en el tiempo dentro del mercado turístico y ha alimentado el flujo de visitantes.

Los eventos tienen otros importantes papeles que van desde la construcción de comunidad hasta la renovación urbana (Getz, 2008: 403). En el primer punto, tienen efectos positivos para los ciudadanos e instituciones de la ciudad, ya que suponen transmitir valores relacionados con el orgullo de pertenencia o vivencia (Muñiz y Cervantes, 2010: 134).

3 DMO son las siglas del término inglés Destination Marketing Organization (Sheehan et al., 2016). 
Poseen un gran potencial para crear un ambiente urbano y un sentido de lugar (González y Morales, 2017: 340). Aunque también se ha señalado que algunos eventos culturales no transcienden ni percolan a la ciudadanía (Rodríguez, 2015: 77). No obstante, aunque la población local no visite sus lugares patrimoniales, solo el conocimiento de que existen construye un sentimiento de orgullo y de continuidad en la comunidad (Timothy, 2011: 32). De hecho, los eventos se pueden emplear para alentar la participación de los residentes y para fomentar los vínculos entre una atracción turística y su comunidad local (Light, 1996: 183). Darían lugar a un fortalecimiento del sentido de comunidad (Sharpley y Stone, 2012). Se trataría de un aumento del sentimiento de orgullo local debido a la celebración del evento (González y Morales, 2017: 356). Por otro lado, aquellos que celebran hitos o temas históricos, como el estudio de caso aquí realizado, también tienen una funcionalidad educativa evidente (Light, 1996: 183). En este sentido, se identifican cada vez más como beneficiosos para la visita de sitios patrimoniales (Prentice, 1993). Aprender es uno de los resultados obtenidos por la participación en eventos culturales (Light, 1996: 188)

Se ha de tener también en cuenta que las políticas para la revitalización urbana se inspiran fuertemente en las posibilidades de la explotación del potencial cultural de los centros históricos (Jansen Verbeke y Lievois, 1999: 81). Los eventos son frecuentemente utilizados como estrategia de revitalización urbana (Smith, 2012) y turística (Richards y Palmer, 2010). En otras ocasiones, sin embargo, muchos de los proyectos no tienen ningún tipo de continuidad y pasado el evento apenas queda un eco (Rodríguez, 2015: 77). En cualquier caso, los sitios patrimoniales son lugares que se transforman, de forma temporal o más permanente, por eventos y festivales (Lovell y Bull, 2017).

A más largo plazo, sin embargo, los eventos pueden sufrir un efecto de disminución, por el cual se requerirán mayores niveles de inversión para generar números de visitantes similares (Richards, 2005: 236). La multiplicación de eventos y festivales pone cada vez más énfasis en la novedad y el espectáculo como la motivación básica para la asistencia (Britton, 1991). No obstante, esto puede originar que muchos eventos pueden terminar banalizando los recursos patrimoniales y ofreciendo productos estandarizados o basados en valores falsos (Silva y Fernández, 2008: 85). La tradición original puede ser transformada en una hipertradición más comercial bastante diferente de sus orígenes culturales primigenios (Landford, 2007). El resultado es un escenario museificado, preparado para el turismo, que ofrece la cultura como simulacro. También se utiliza el término festivilización (Cudny, 2016) para describir cómo las ciudades sobreexplotan los eventos culturales (Getz, 2008: 422). O se habla de turistificación de los eventos (González y Morales, 2017: 339). Se trata del riesgo de vincularlos a estrategias de desarrollo turístico por encima de los aspectos sociales y culturales de la celebración (Getz, 1989). Sucede cuando hay una desnaturalización de las narrativas y de la identidad local para adaptarlas al evento (González y Morales, 2017: 341). En muchos destinos turísticos tiene lugar, en realidad, un contacto somero con el patrimonio local a través de la asistencia a unos cuantos eventos (De la Calle, 2013: 214).

Finalmente, determinados destinos o comunidades pueden llegar a alcanzar un grado de saturación del turismo de eventos (Getz, 2008:419). Sería el resultado de una profusión constante de celebración de acontecimientos que llevaría a la pérdida de singularidad y unicidad intrínsecas de los mismos. Además, la constante afluencia extraordinaria de visitantes por la celebración repetida de eventos puede crear una respuesta negativa 
hacia la actividad turística en la comunidad anfitriona. Incluso, el éxito de afluencia de algunos eventos culturales da pie a problemas de saturación poniendo en riesgo no solo el acontecimiento sino la imagen del mismo (Richards y Ruiz, 2017: 5). El incremento de visitantes es el objetivo principal del turismo de eventos, sin importar habitualmente si la capacidad de acogida es rebasada. Esto puede conllevar un deterioro del propio evento y de la actividad turística (García y De la Calle, 2012).

\section{METODOLOGÍA}

El estudio de casos cualitativos es un enfoque de investigación que facilita la exploración de un fenómeno dentro de un contexto específico utilizando una variedad de fuentes de datos (Baxter y Jack, 2008). La presente investigación adopta el tipo de estudio de caso único explicativo (Yin, 2003). Este método permite responder las preguntas de investigación planteadas (Piva et al., 2017: 100). En este artículo, el objeto de estudio cualitativo elegido es el evento distintivo del IV Centenario de la muerte del Greco, celebrado en Toledo en 2014. Así, el área de estudio escogida es un destino turístico cultural consolidado español (Escudero, 2018). Hay una fuerte vinculación del evento celebrado con un lugar, Toledo, donde el turismo es central en la economía urbana. El artículo se fundamenta en un análisis post evento siguiendo la recomendación del especialista en este campo de estudio Getz (2008: 417). Dentro de los posibles métodos de investigación sobre turismo de eventos apuntados por Getz (2008), se opta por una revisión literaria; por la observación directa; por el estudio de fuentes, la encuesta de ocupación hotelera del Instituto Nacional de Estadística (INE, en red) y la memoria del evento (Fundación El Greco 2014, 2015); y, principalmente, por un método fenomenológico a través de una encuesta. Se trata de una investigación basada en un examen conceptual y empírico.

La realización de encuestas es una metodología ampliamente extendida en las ciencias sociales (Babbie, 2015). Se ha utilizado de manera muy profusa en las investigaciones relativas al turismo en general (Comisión Europea, 2016) y al cultural en particular (Richards, 2007; Richards y Munsters, 2010). Se ha señalado como un posible método de investigación en el turismo de eventos (Getz, 2008: 420). Richards (2017) plantea una metodología a través de encuestas para medir las experiencias en los eventos en diferentes países. En un estudio de caso centrado en el centro histórico de Salamanca, Cavaillès et al. (2016) utilizaron como método un cuestionario aplicado a los turistas. En otro estudio de caso, esta vez del Festival Internacional Cervantino de la ciudad mexicana de Guanajuato, Barrera y Hernández (2017) emplearon como método una encuesta aplicada también a los turistas. Con el fin de analizar las percepciones de la comunidad anfitriona sobre los impactos sociales y culturales del turismo, Backman, Hsu y Backman (2011) optaron un cuestionario entre los residentes. Otras veces se ha abordado la percepción conjunta de visitantes y residentes (Weaver y Lawton, 2013) y ambas perspectivas son interesantes (Romero y Alvarado, 2017: 57). En este artículo se combinarán ambos grupos (como también optan Richard y Wilson, 2004, Piva et al., 2017 y Romero y Alvarado, 2017). Así, la encuesta se realiza tanto a turistas como a residentes.

Se han empleado cuestionarios estructurados como metodología principal para llevar a cabo la investigación, al igual que hacen Piva et al. (2017). La encuesta se realiza cara a cara 
mediante estos cuestionarios a pie de calle a visitantes escogidos al azar en el centro histórico y a residentes elegidos aleatoriamente en toda la ciudad de Toledo. Si bien en investigaciones anteriores las encuestas se llevaron a cabo en los lugares concretos de celebración del evento (Ruiz, 2017: 36), y así también realizó su estudio la Fundación El Greco 2014 (2015: 187), se ha preferido pasar los cuestionarios por el casco antiguo a los visitantes y en toda la ciudad a los residentes. Se eligió de este modo el espacio de mayor frecuencia turística en la ciudad (Troitiño, 2005) para los primeros, pero huyendo de los lugares con referencias al Año Greco. El objetivo era saber realmente si los visitantes tenían conocimiento o no del evento. A la comunidad anfitriona se prefirió captarla en diferentes barrios de Toledo, no solo en el centro histórico. Con ello, se evitaba el sesgo que podría surgir si solo se preguntaba a residentes próximos al lugar físico de celebración de los actos del evento.

La encuesta tuvo lugar a lo largo del mes de noviembre y hasta el 9 de diciembre de 2014. Se escogió realizar el cuestionario en las fechas finales de celebración del evento para poder tener una perspectiva más amplia. Los visitantes que llegaban a Toledo habían tenido la oportunidad suficiente de recibir información sobre el centenario y los residentes para conocer y acudir a algún acto del mismo. También se prefirió hacer entrevistas directas antes que un cuestionario por correo, teléfono o en línea. La encuesta tuvo limitaciones de tiempo y financiación, como la llevada a cabo por Ram, Björk y Weidenfeld (2016). Sin embargo, si estos autores optaron un cuestionario de autorreporte (Ram, Björk y Weidenfeld, 2016: 113), aquí se ha procurado realizar entrevistas cara a cara (al igual que hace Ruiz, 2017). La citada Fundación El Greco 2014 (2015: 187), con otro presupuesto, hizo un perfil del visitante de las exposiciones principales del evento con la empresa especializada en la realización de encuestas Metroscopia. Aquí, se ha optado por encuestadores entrenados ${ }^{4}$ que cubriesen los cuestionarios con las respuestas de los entrevistados.

\section{Cuadro 1}

\section{FICHA TÉCNICA DEL ESTUDIO}

\begin{tabular}{|l|c|c|}
\hline & VISITANTES & RESIDENTES \\
\hline Universo poblacional & \pm 3.000 .000 & 83.334 (padrón municipal 2014) \\
\hline Tamaño muestral $(\mathrm{n})$ & 270 & 273 \\
\hline Nivel de confianza & $\pm 5,96 \%$ & $\pm 5,92 \%$ \\
\hline Error muestral (supuesto $\mathrm{p}=\mathrm{q}=50 \%$ ) & \multicolumn{2}{|c|}{ Encuesta personal cara a cara } \\
\hline Técnica & \multicolumn{2}{|c|}{ Excel 2013 } \\
\hline Trabajo de campo y hasta el 9 de diciembre de 2014 \\
\hline Programa informático & \multicolumn{2}{|c|}{ Excel } \\
\hline
\end{tabular}

4 La encuesta fue realizada por alumnos de la asignatura Turismo y Patrimonio del $4^{\circ}$ de Grado de Humanidades y Patrimonio de la Facultad de Humanidades de Toledo. Se sigue el ejemplo de Ruiz (2017), donde estudiantes de la licenciatura en Administración de Recursos Turísticos realizaron la encuesta de la investigación. De manera general, los encuestados respondieron positivamente al ver que el cuestionario lo realizaba un estudiante para un «trabajo de la Universidad». 
Se realizaron 546 encuestas, de las cuales fueron válidas 543, 270 entre visitantes y 273 entre residentes (cuadro 1). Se reconoce que es una muestra pequeña, pero se considera suficiente para realizar comparaciones estadísticas entre dos grupos. Encontramos en la literatura académica relacionada con el turismo cultural la utilización de muestras de un tamaño similar al empleado en el presente artículo y para múltiples temas investigados. Light, en su estudio sobre las características del público de los eventos en sitios patrimoniales, realizó una encuesta en el castillo de Caerphilly, en el suroeste de Gales, durante la celebración de recreaciones históricas y en los días de visita normal. Su investigación se realizó con cuestionarios a un total de 253 visitantes, 173 en días sin evento y 80 en días con evento (Light, 1996: 186). Littrell, Anderson y Brown (1993) utilizan una muestra de 385 turistas en el área del Medio Oeste de Estados Unidos para su relevante artículo sobre qué hace que un souvenir artesanal sea auténtico. Oom do Valle, Mendes y Guerreiro (2012) hacen 384 cuestionarios a escala regional para investigar sobre los eventos culturales en el área portuguesa del Algarve. Ram, Björk y Weidenfeld (2016) realizan 373, divididos, además, entre dos destinos, Helsinki y Jerusalén, y en cuatro atracciones turísticas en total. Piva et al. (2017: 101) también optan por un número limitado de 220 encuestados. En el estudio de caso de Barrera y Hernández (2017) del Festival Internacional Cervantino en Guanajuato (México) se utiliza una muestra similar, 230 personas entrevistadas. Este mismo evento ha sido objeto de atención de Ruiz (2017), quien realizó 372 encuestas.

El cuestionario realizado recoge el sexo, la edad y el lugar de procedencia, en el caso de los visitantes, o el origen, en el caso de los residentes (cuadro 2). Su diseño se ajusta a las preguntas de la investigación relativas al conocimiento y participación del evento de locales y foráneos. Sus hallazgos serán presentados en el siguiente apartado. El cuestionario consta de otros puntos que no son abordados por el estudio actual. Los resultados empíricos obtenidos son analizados con una inferencia estadística a través de cálculos aritméticos de porcentajes. En cualquier caso, las cifras finales deben tenerse en cuenta con cierto grado de precaución y no deben considerarse como definitivas.

Cuadro 2

CARACTERÍSTICAS DEMOGRÁFICAS DEL ESTUDIO

\begin{tabular}{|l|l|c|c|c|}
\hline & & VISITANTES (n=270) & $\begin{array}{c}\text { RESIDENTES } \\
(\mathrm{n}=273)\end{array}$ & $\begin{array}{c}\text { TOTAL } \\
(\mathrm{n}=543)\end{array}$ \\
\hline \multirow{2}{*}{$\begin{array}{l}\text { Sexo } \\
(\mathrm{n}=543)\end{array}$} & Hombres & $48,1 \%$ & $47,9 \%$ & $48 \%$ \\
\cline { 2 - 5 } & Mujeres & $51,9 \%$ & $52,1 \%$ & $52 \%$ \\
\hline \multirow{3}{*}{$\begin{array}{l}\text { Edad }(\mathrm{n}=541) \\
\end{array}$} & Menos de 30 años & $27,2 \%$ & $32,9 \%$ & $30,1 \%$ \\
\cline { 2 - 5 } & $30-39$ años & $23,8 \%$ & $14,8 \%$ & $19,3 \%$ \\
\cline { 2 - 5 } & $40-49$ años & $17,7 \%$ & $15,3 \%$ & $16,4 \%$ \\
\cline { 2 - 5 } & $50-59$ años & $16,1 \%$ & $21,9 \%$ & $19,1 \%$ \\
\cline { 2 - 5 } & 60 o más años & $15,2 \%$ & $15,1 \%$ & $15,1 \%$ \\
\hline
\end{tabular}




\begin{tabular}{|c|c|c|c|c|}
\hline & & VISITANTES $(n=270)$ & $\begin{array}{l}\text { RESIDENTES } \\
\quad(\mathrm{n}=273)\end{array}$ & $\begin{array}{l}\text { TOTAL } \\
(\mathrm{n}=543)\end{array}$ \\
\hline \multirow{2}{*}{$\begin{array}{l}\text { Lugar de } \\
\text { procedencia } \\
(\mathrm{n}=270)\end{array}$} & Internacionales & $38,1 \%$ & --- & --- \\
\hline & Nacionales & $61,9 \%$ & --- & ---- \\
\hline \multirow{5}{*}{$\begin{array}{l}\text { Lugar de } \\
\text { origen } \\
(n=271)\end{array}$} & Toledo & --- & $64,1 \%$ & --- \\
\hline & Provincia & --- & $19,9 \%$ & ---- \\
\hline & $\begin{array}{l}\text { Castilla-La } \\
\text { Mancha }\end{array}$ & ---- & $3,3 \%$ & --- \\
\hline & Resto de España & --- & $11,6 \%$ & --- \\
\hline & Extranjeros & --- & $1,1 \%$ & --- \\
\hline
\end{tabular}

\section{RESULTADOS: ANÁliSIS POST EVENTO DEL IV CENTENARIO DE LA MUERTE DEL GRECO EN TOLEDO}

\subsection{Un evento cultural distintivo de gran éxito: más turistas, más ingresos y la per- manencia de los Espacios Greco}

El Greco es un personaje reconocido mundialmente dentro de las artes plásticas. Por esta razón, la celebración de su centenario entra dentro de las convocatorias que pueden alcanzar gran difusión a nivel internacional (Rodríguez, 2015: 69). Las ciudades históricas recurren a personalidades notables de su pasado para crear una identidad y una imagen singular. En Granada, por ejemplo, Federico García Lorca es uno de los principales elementos que conforman la actual marca ciudad. Se habla de la «Granada lorquiana» (Salguero, 2016: 256). En Málaga ha habido un proceso de tematización de la ciudad en torno a Picasso (Barrera, 2013). En Toledo, la relación entre el Greco y el turismo se sitúa ya a inicios del siglo XX. En un primigenio estudio sobre el turismo en la ciudad de 1927, Camarasa afirmaba que «Toledo es la base del turismo nacional, el Greco es la base del turismo toledano» (cita extraída de García Álvarez, 2007: 204). El Greco se convirtió en uno de los principales reclamos y señas de identidad para la patrimonialización y el inicial impulso turístico de la ciudad (García Álvarez, 2007: 205). Sin duda es parte de las imágenes históricas que han creado una identidad urbana de Toledo ${ }^{5}$. El historiador Martínez califica este proceso como «la invención de Toledo», refiriéndose a la exaltación de un pasado glorioso y selectivamente recordado para encontrar una imagen ideal (Martínez, 2007: 121).

En el año 2014 se cumplían 400 años de la muerte del pintor cretense. A raíz de esta efeméride se organizó el IV Centenario de la muerte del Greco en la ciudad de Toledo, donde el pintor falleció tras haber realizado allí el grueso principal de su obra. Se realizó, por tanto, un tipo de celebración cultural, una conmemoración, siguiendo la tipología de

5 No es el único personaje histórico explotado turísticamente en Toledo. Por ejemplo, existe la ruta de las Huellas de Teresa de Jesús (Ayuntamiento de Toledo, 2017) 
eventos planeados de $\operatorname{Getz}^{6}$ (2008: 404); aunque también relacionada con los eventos de arte dado que la pintura es un elemento fundamental. Además, encajaría dentro de la definición de Ritchie (1984:2) de los eventos distintivos o de sello (hallmark events) al ser un acontecimiento importante de una sola vez claramente desarrollado para mejorar la rentabilidad de Toledo como destino turístico. También responde a la definición dada por Jago y Shaw (1998: 28-29) para acotar los eventos especiales (special events) al cumplir con los atributos principales que deben tener estos acontecimientos: ser único y extraordinario, tener un gran impacto económico, atraer la atención de los medios, elevar la imagen o el perfil de la región local, ser ocurrencias infrecuentes o excepcionales, tener una duración limitada, ofrecer una experiencia social y contribuir al desarrollo del turismo. De hecho, se trata de un evento que declara tener como objetivo principal la promoción del turismo y la atracción de turistas. Entre los objetivos fijados se especifica el de «impulsar y dinamizar las actividades culturales, turísticas, económicas y empresariales» (Fundación El Greco 2014, 2015: 10). Siguiendo la clasificación de González y Morales (2017: 342), sería un evento cultural orientado al turismo ${ }^{7}$ fundamentado en los valores del patrimonio local (el legado del Greco). En un estudio previo sobre la capacidad de acogida de visitantes se calificaba de hecho al Año Greco como un proyecto turístico-cultural (Universidad Complutense, en red).

En definitiva, estamos ante un evento cultural, una conmemoración histórica y artística, con un carácter distintivo y excepcional. Un acontecimiento que ofrecía las cuatro dimensiones experienciales que desean los consumidores según Pine y Gilmore (1999); educación, a través del aprendizaje sobre el Greco y su contexto histórico; escapismo, mediante la evasión de la rutina habitual con la participación en un evento único y en el marco de la ciudad patrimonial de Toledo; estética, aportada por las pinturas del Greco, y entretenimiento, a través de una actividad de ocio como es el turismo cultural.

El IV Centenario de la muerte del Greco se desarrolló en Toledo durante el 2014 mediante un amplio programa oficial (Fundación El Greco 2014, 2015). Los actos culturales principales fueron las exposiciones, fundamentalmente; el festival de artes escénicas PaseArte y el de Música del Centenario. Además, tuvieron lugar otras actividades desde simposios académicos hasta diferentes actos de homenaje o el festival gastronómico SaboreaGreco. Se estableció un calendario expositivo a lo largo de todo el año con el fin de evitar una estacionalidad en la asistencia del evento, cuestión que se logró (Recuero, Blasco y García de Madariaga, 2016: 55). Tuvieron lugar tres grandes exposiciones temporales, una en el Museo del Prado de Madrid y dos en el toledano Museo de Santa Cruz como sede principal: El Griego de Toledo y El Greco: Arte y Oficio. El éxito de la primera gran muestra, El Griego de Toledo, celebrada entre el 14 de marzo y el 14 de junio de

6 Getz (2008) distingue entre celebraciones culturales; políticas y estatales; de arte y entretenimiento; de negocios y comercio; educativas y científicas; de competencia deportiva; recreativas y privadas.

7 González y Morales (2017: 342) distinguen entre eventos orientados al turismo, parcialmente orientados al turismo, con capacidad de atracción de turistas, transformados por el turismo y eventos turísticos. Se deduce que los eventos turísticos estarían exclusivamente dedicados a la atracción de visitantes. El Año Greco no fue un evento sólo para el turismo (entre sus objetivos aparecen también múltiples aspectos socioculturales como avanzar en el mejor conocimiento del personaje y su obra o enriquecer la identidad de Toledo mediante su relación con el Greco -Fundación El Greco 2014, 2015: 10), pero sí claramente orientado al mismo. 
2014, retroalimentó el interés por el centenario y «la convirtió en una de las más destacadas propuestas culturales del año en España» (Fundación El Greco 2014, 2015: 187).

\section{Figura 1 \\ ESPACIOS Y MUSEOS GRECO EN TOLEDO}

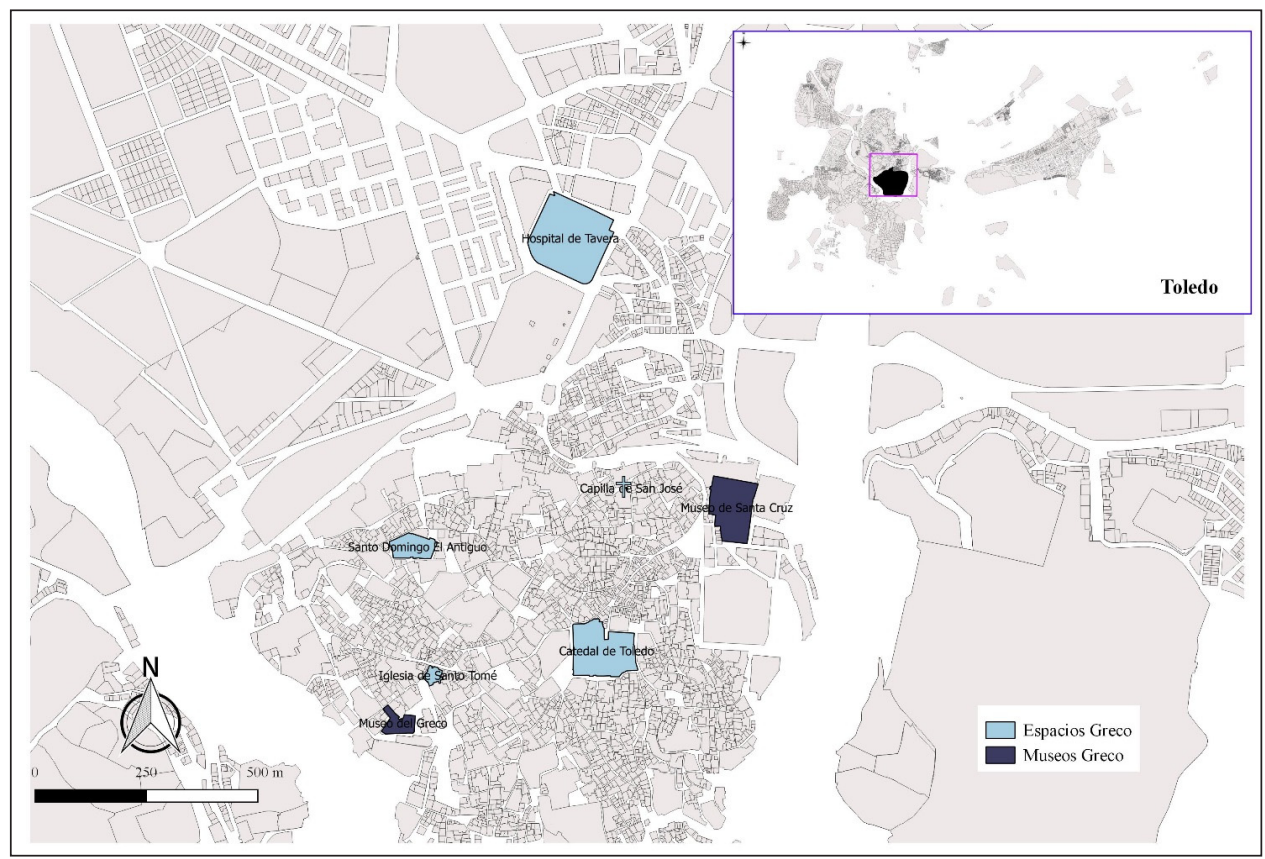

Fuente: Elaboración propia a partir de base cartográfica del CNIG (en red).

Por otro lado, en la ciudad se crearon los Espacios Greco. Se trata de 5 lugares patrimoniales de Toledo con ejemplos de su obra artística: la capilla de San José ${ }^{8}$, el convento de Santo Domingo el Antiguo, la sacristía de la catedral de Toledo, el Hospital Tavera y la iglesia de Santo Tomé (figura 1). En este último caso, se encuentra abierto al público, previo pago de entrada, el cuadro de gran tamaño El entierro del Conde de Orgaz. Esta obra, de por sí, ya era uno de los principales atractivos turísticos de la ciudad (Troitiño y Troitiño, 2010: 100). Sin embargo, otros lugares que también eran previamente visitables adquieren ahora una nueva dimensión con el evento: el Hospital de Tavera aumentó de sus 12.000 visitantes anuales a más de 115.000 (Fundación El Greco 2014, 2015: 88). Entre estos espacios se establece una ruta que el visitante debía recorrer. En la escala local, las rutas que conectan los sitios patrimoniales funcionan para unir lugares individuales para

8 Es de propiedad privada y nobiliaria. Se abrió al público por primera vez en la historia durante tres meses. Por su pequeño tamaño se estableció un ritmo de visita de 15 personas cada 15 minutos (hoy solo es visitable con reserva telefónica previa). La fuerte demanda no pudo ser atendida por esta causa (Fundación El Greco 2014, 2015: 85-86). Es otra evidencia del éxito alcanzado por el Año Greco en Toledo. 
turistas más que por la importancia de su contexto histórico (Timothy y Boyd, 2006: 9). Evidentemente no hay una conexión histórica real en la ruta de los Espacios Greco. Simplemente, se unen espacios que hoy albergan su legado y se incentiva al visitante que los recorra. Se trataba de aportar un nuevo itinerario a la ciudad (Fundación El Greco 2104, 2015: 83). Toledo se caracteriza por su gran disponibilidad de Patrimonio. No obstante, la mayoría de sus visitantes se distribuyen en unos pocos ejemplos y se mueven por una misma ruta turística predominante (Troitiño y Troitiño, 2009 y Escudero, 2018). Los Espacios Greco ampliaban y renovaban la oferta de sitios patrimoniales visitables. Con este motivo fueron remodelados, adaptados a la visita o restaurados (Fundación El Greco $2014,2015: 84)$. Creaban un recorrido alternativo. Se revalorizaban y visibilizaban lugares (Fundación El Greco 2014, 2015: 83) a través de su identidad con el pintor y formando un conjunto y un producto turístico patrimonial. Tras el Año Greco, se han mantenido estos espacios de manera permanente en Toledo y se le han añadido los museos de Santa Cruz, con obras del pintor en su exposición permanente, y del Greco, museo de titularidad estatal reabierto en 2011 (figura 1). Hoy forman una oferta turística cultural denominada El Greco en Toledo. El legado físico principal del evento ha sido precisamente este, la continuación en el tiempo del acontecimiento a través de la permanencia de los Espacios Greco.

El evento fue organizado por una entidad, una institución de carácter público, creada específicamente para tal fin en 2010: la Fundación El Greco 2014. El DMO del Año Greco tuvo como fundadores a la administración estatal, el Ministerio de Educación, Cultura y Deporte; la autonómica, la Junta de Castilla-La Mancha; la provincial, la Diputación Provincial de Toledo; la local, el Ayuntamiento de Toledo, y la Iglesia católica, el Arzobispado de Toledo. De esta forma, estaban representadas todas las escalas administrativas del país y la Iglesia, propietaria de parte del patrimonio empleado en el evento. Tuvo la presidencia de honor de los Reyes de España. Dentro de su organigrama, además de una comisión ejecutiva, órgano encargado para el desarrollo de las funciones rectoras, también contó con un consejo asesor de la Fundación formado por expertos en la gestión del Patrimonio (Fundación El Greco 2014, 2015). Tras la celebración del evento, esta institución desaparece y su legado es asumido por la Real Fundación de Toledo (Agencia Efe, 2015), una institución cultural privada sin ánimo de lucro constituida en 1988 cuyo fin es contribuir a la conservación y revitalización de la ciudad histórica de Toledo (Real Fundación de Toledo, en red).

Según Stokes (2004), en la organización de eventos es habitual la constitución de una red de agentes interesados dominados por una agencia pública. La colaboración o alianzas entre sectores privados, públicos y sin fines de lucro es crucial (Timothy y Boyd: 2006: 10). De esta forma, otras instituciones también colaboraron con la conmemoración como el organismo público responsable del marketing de España como destino de viajes en el mundo, Turespaña, o como la Universidad de Castilla-La Mancha. También fueron colaboradores del evento la Asociación de Hostelería y Turismo de Toledo, un agente local turístico relevante, y la Fundación de la Caja Castilla-La Mancha, entre otros. El centenario contó además con importantes patrocinadores privados: la Fundación Mapfre, Telefónica, Nestlé, la Fundación BBVA, La Caixa, Iberdrola, Endesa, etc ${ }^{9}$. El IV Centena-

9 La lista completa de fundadores, instituciones colaboradoras, colaboradores, patrocinadores oficiales, patrocinadores y patrocinadores de los medios de comunicación se puede consultar en la memoria de actividades del evento (Fundación El Greco 2014, 2015). 
rio de la muerte del Greco como acontecimiento de excepcional interés público otorgaba a los patrocinadores los mayores incentivos fiscales que concede la legislación española. De hecho, la participación privada fue fundamental. La financiación del programa de actividades se hizo básicamente a través de este patrocinio (Fundación El Greco 2014, 2015). Así, el proyecto tuvo un presupuesto de 20 millones de euros, suma de los 12 millones de euros de patrocinios privados y de la valoración de los descuentos en publicidad y difusión (Fundación El Greco 2014, 2015: 187). Según el balance final, el propio ente gestor tuvo un saldo final ligeramente positivo de 98.598 euros sumando la cuenta de resultados de los años 2013 y 2014 (Fundación El Greco 2014, 2015: 193).

El Año Greco supuso un impulso para el turismo de la ciudad de Toledo. Fue un empuje extra para la actividad turística de la ciudad toledana aumentando durante 2014 el número de visitantes a la ciudad y el beneficio económico generado por los mismos. Se analizan ambos aspectos, comenzando por el incremento de la afluencia turística

Es un hecho que la venta de entradas de las dos exposiciones, sobre todo la primera y principal, El Griego de Toledo, fue un éxito. Esta exposición tuvo 231.666 visitantes en su sede principal, el museo de Santa Cruz, y la de El Greco: Arte y Oficio, 90.064 en el mismo espacio (Fundación El Greco 2014: 191). El éxito de afluencia de algunos eventos culturales da pie a problemas de saturación de visitantes poniendo en riesgo no solo el acontecimiento sino la imagen del mismo (Richards y Ruiz, 2017: 5). La fuerte demanda hizo adoptar un sistema de venta de entradas anticipadas vía internet y telefónica. Aun así, la masiva llegada de público llegó a crear problemas para acceder al Museo de Santa Cruz, formándose largas colas en su entrada. Por esta razón, la Fundación El Greco 2014 tuvo que establecer la obligación de cerrar de manera previa el día y la hora de visita (ABC, 2014). Con este sistema se podía respetar el aforo fijado para el recinto expositivo (Fundación El Greco 2014, 2015: 20) por el citado estudio universitario previo de la capacidad de acogida (Universidad Complutense, en red). No obstante, esto dio lugar a que las entradas se agotasen, en especial los festivos y fines de semana, y que muchos visitantes que no las hubiesen comprado con antelación no pudieran acceder a las exposiciones (sobre todo a la primera, la más demandada).

\section{Cuadro 3}

\section{VIAJEROS Y PERNOCTACIONES EN TOLEDO: 2000-2017}

\begin{tabular}{|c|c|c|c|c|c|}
\hline \multicolumn{3}{|c|}{ Viajeros } & \multicolumn{3}{c|}{ Pernoctaciones } \\
& & Var. & & & Var. \\
\cline { 3 - 4 } Año & Total & $\begin{array}{c}\text { anual } \\
(\%)\end{array}$ & Año & Total & $\begin{array}{c}\text { anual } \\
(\%)\end{array}$ \\
\hline 2000 & 389.856 & ---- & 2000 & 568.398 & ---- \\
\hline 2001 & 391.574 & 0,44 & 2001 & 596.170 & 4,89 \\
\hline 2002 & 379.302 & $-3,13$ & 2002 & 590.298 & $-0,98$ \\
\hline 2003 & 375.985 & $-0,87$ & 2003 & 575.804 & $-2,46$ \\
\hline
\end{tabular}




\begin{tabular}{|r|r|r|r|r|r|}
\hline 2004 & 412.495 & 9,71 & 2004 & 639.269 & 11,02 \\
\hline 2005 & 434.615 & 5,36 & 2005 & 677.065 & 5,91 \\
\hline 2006 & 450.669 & 3,69 & 2006 & 729.706 & 7,77 \\
\hline 2007 & 465.418 & 3,27 & 2007 & 742.054 & 1,69 \\
\hline 2008 & 448.007 & $-3,74$ & 2008 & 728.138 & $-1,88$ \\
\hline 2009 & 441.644 & $-1,42$ & 2009 & 694.483 & $-4,62$ \\
\hline 2010 & 460.795 & 4,34 & 2010 & 719.281 & 3,57 \\
\hline 2011 & 462.063 & 0,28 & 2011 & 718.745 & $-0,07$ \\
\hline 2012 & 468.633 & 1,42 & 2012 & 700.796 & $-2,50$ \\
\hline 2013 & 491.362 & 4,85 & 2013 & 738.586 & 5,39 \\
\hline $\mathbf{2 0 1 4}$ & $\mathbf{5 9 3 . 0 2 8}$ & $\mathbf{2 0 , 6 9}$ & $\mathbf{2 0 1 4}$ & $\mathbf{8 9 8 . 5 4 7}$ & $\mathbf{2 1 , 6 6}$ \\
\hline 2015 & 566.977 & $-4,39$ & 2015 & 849.133 & $-5,50$ \\
\hline 2016 & 591.225 & 4,28 & 2016 & 907.897 & 6,92 \\
\hline 2017 & 617.584 & 4,46 & 2017 & 917.180 & 1,02 \\
\hline
\end{tabular}

Fuente: encuesta de ocupación hotelera (INE, en red).

En sistemas abiertos como el centro histórico de Toledo es complicado y muy costoso saber realmente cuántos visitantes hay en un periodo de tiempo. La estimación más aceptada en el ámbito académico está en torno a los dos millones de visitantes anuales (Escudero, 2018). La Fundación El Greco 2014 (2015: 187) aumenta esa cifra hasta los 3 millones en el año del evento. Con un carácter más documentado tenemos las cifras de la encuesta de ocupación hotelera del INE (en red), fuente habitual en los estudios turísticos en España. Según esta fuente, el Año Greco fue un hito en la evolución del número de viajeros y de pernoctaciones en el destino turístico de Toledo en el siglo XXI (cuadro 3). En el 2014, la ciudad tuvo 593.028 viajeros, un $20,69 \%$ más que en el año anterior. El total de pernoctaciones fue de 898.547 , un 21,66\% más que en 2013. Estos incrementos, superiores al 20\%, son únicos en toda la evolución de la ocupación hotelera de Toledo desde 2000. El año posterior, 2015, no pudo mantener estas cifras y ambos conceptos, viajeros y pernoctaciones, descendieron entre un 4-5\%. Solo el incremento del turismo cultural en el presente, con un aumento anual de más de un $4 \%$, ha logrado ya superar el hito del Año Greco. Sin duda, se trata de un punto de inflexión en la afluencia turística de Toledo. Supuso un incremento sustancial del número de visitantes sin precedentes ni, de momento, posteriores similares.

También resulta ser extremadamente difícil estimar cuantitativamente el impacto económico real del turismo en una ciudad. Sin embargo, es fácil de imaginar que un aumento semejante de afluencia supuso un incremento de los ingresos generados por la actividad turística en el año 2014 gracias a la celebración del evento. La memoria de actividades del IV Centenario de la muerte del Greco cuantifica los ingresos obtenidos. El impacto económico del evento se cifra en 367,8 millones de euros: 203 directos, 69,6 indirectos y 94,8 inducidos (Fundación El Greco 2014, 2015: 188). Esto daría un factor multiplicador de más de 18 euros por cada euro invertido. 


\section{Cuadro 4}

ESTABLECIMIENTOS HOTELEROS ABIERTOS, SU NÚMERO DE PLAZAS Y EL GRADO DE OCUPACIÓN MEDIO POR PLAZAS: 2005-2017

\begin{tabular}{|c|c|c|c|}
\hline Año & $\begin{array}{c}\mathbf{N}^{\mathbf{0}} \text { máximo de } \\
\text { establecimientos abiertos } \\
\text { durante el año }\end{array}$ & $\begin{array}{c}\mathbf{N}^{\mathbf{0}} \text { máximo de plazas } \\
\text { durante el año }\end{array}$ & $\begin{array}{c}\text { Grado de ocupación } \\
\text { medio por plazas }\end{array}$ \\
\hline 2005 & 62 & 3.884 & $50,13 \%$ \\
\hline 2006 & 64 & 4.096 & $50,36 \%$ \\
\hline 2007 & 65 & 4.124 & $49,39 \%$ \\
\hline 2008 & 67 & 4.398 & $46,74 \%$ \\
\hline 2009 & 67 & 4.472 & $43,2 \%$ \\
\hline 2010 & 65 & 4.382 & $45,09 \%$ \\
\hline 2011 & 66 & 4.484 & $44,36 \%$ \\
\hline 2012 & 68 & 4.481 & $42,5 \%$ \\
\hline 2013 & 68 & 4.543 & $44,47 \%$ \\
\hline $\mathbf{2 0 1 4}$ & $\mathbf{6 8}$ & $\mathbf{4 . 5 3 0}$ & $\mathbf{5 4 , 3 1 \%}$ \\
\hline 2015 & 68 & 4.517 & $51,16 \%$ \\
\hline 2016 & 65 & 4.436 & $55,49 \%$ \\
\hline 2017 & 65 & 4.450 & $57 \%$ \\
\hline
\end{tabular}

Fuente: encuesta de ocupación hotelera (INE, en red).

A través de la encuesta de ocupación hotelera (INE, en red) se puede constatar si el incremento de turistas y gastos se vio reflejado en el aumento de la planta turística, en concreto en el sector del alojamiento (cuadro 4). En este sentido, el evento del Año Greco no tuvo una consecuencia física ni tanto en el número máximo de establecimientos hoteleros abiertos (68) ni en el número máximo de plazas disponibles durante el año (4.530). No hay una relación entre el evento significativo y un mayor desarrollo de hoteles y plazas en el destino turístico Toledo. Sin embargo, durante 2014 se produce un notable incremento del grado de ocupación medio por plazas, que se sitúa en el 54,31\%, mientras que en el 2013 fue del 44,47\%. La celebración de la conmemoración supuso un ascenso en el uso medio de la oferta hotelera de más de 10 puntos porcentuales, superando la ocupación media registrada desde 2005. Sólo el incremento actual del turismo cultural en Toledo ha rebasado la cifra de 2014 con un grado de ocupación media del 55,49\% en 2016 y del $57 \%$ en 2017.

El primer objetivo clásico de la política turística ha sido perseguir el crecimiento de la actividad (Velasco, 2016: 580). El evento del Año Greco fue un gran éxito bajo este prisma de análisis. De hecho, los excelentes resultados obtenidos con esta conmemoración han dado lugar a que la ciudad haya seguido apostando por la celebración de eventos distintivos y la creación de nuevos productos turísticos. Solo dos años después, Toledo es elegida 
como Capital Española de la Gastronomía. A lo largo de 2016 tuvo lugar así un completo calendario de actos que relacionaban la cultura y el patrimonio con la gastronomía. Los sitios patrimoniales toledanos fueron el marco para diferentes propuestas gastronómicas (figura 2). En 2017, la promoción turística de la ciudad se orientó a la celebración del 30 aniversario de su declaración como Patrimonio de la Humanidad por la UNESCO (Rico, Parra y Beltrán, 2018). Las cifras de la encuesta de ocupación hotelera reflejan el incremento de viajeros y pernoctaciones en 2016 y 2017 (cuadro 2) así como del grado de ocupación media de las plazas hoteleras (cuadro 3).

\section{Figura 2 \\ ACTO DEL EVENTO GASTRONÓMICO DE 2016 EN EL CENTRO \\ CULTURAL DE SAN MARCOS}

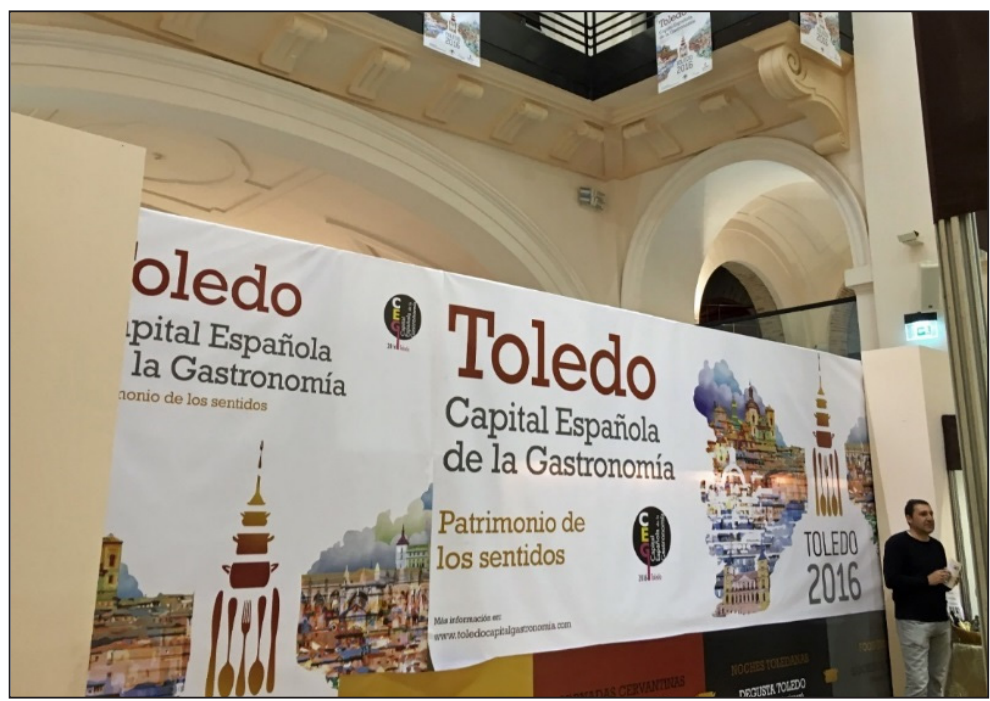

Fotografía del autor, 2 de mayo de 2016.

El modelo de eventos culturales distintivos basados en conmemoraciones ha sido seguido por otras ciudades españolas tras el IV Centenario de la muerte del Greco. En la provincia de Alicante, la ciudad de Orihuela celebró en 2017 su Año Hernandiano al cumplirse el 75 aniversario de la muerte del gran poeta orioliano Miguel Hernández (Ayuntamiento de Orihuela, en red). Desde noviembre de 2017 y durante todo el 2018, Sevilla conmemora el 400 Aniversario del nacimiento del pintor Murillo (Ayuntamiento de Sevilla, en red). Las coincidencias del evento sevillano con el toledano, ambos con una fuerte vocación turística, son evidentes: una programación basada en grandes exposiciones del artista y la creación de un itinerario para recorrer los espacios donde el correspondiente pintor ha dejado su rastro. Si Toledo celebró su Año Greco, Sevilla desarrolla su Año Murillo. 


\subsection{Un gran incentivo para el destino turístico cultural, una identidad para los resi- dentes y una participación menor de la comunidad local}

El éxito alcanzado por el evento distintivo del IV Centenario de la muerte del Greco en Toledo es una evidencia. Sin embargo, la investigación empírica permite matizar algunos aspectos con mayor profundidad. De este modo, se realizó una encuesta $(n=543)$ entre los visitantes $(n=270)$, tanto turistas $(n=141)$ como excursionistas $(n=129)$, y residentes $(n=273)$ durante el mes de noviembre y hasta el 9 de diciembre de 2014.

Comenzando por los visitantes, un primer hecho a valorar es el grado de conocimiento previo que tenían de la celebración del evento en Toledo. Se ha de tener en cuenta que un aspecto fundamental desarrollado fue la promoción del Año Greco con 8.557 apariciones registradas en los medios de comunicación tanto nacionales como internacionales (Fundación El Greco 2014, 2015: 187) y 805.007 visitas en la página web ${ }^{10}$ (Fundación El Greco, 2014, 2015: 168). La difusión de la conmemoración tuvo resultados positivos y el 79,55\% de los visitantes encuestados sabían previamente de la existencia del evento. Sin embargo, aparecen claras diferencias entre viajeros extranjeros y españoles. Entre los visitantes nacionales el conocimiento previo del Año Greco es del 91,81\%, la inmensa mayoría. Pero entre los internacionales, el 37,15\% llegaron a Toledo sin saber que tenía lugar el evento.

\section{Figura 3 \\ CONOCIMIENTO Y PARTICIPACIÓN EN EL AÑO GRECO DE VISITANTES Y RESIDENTES}

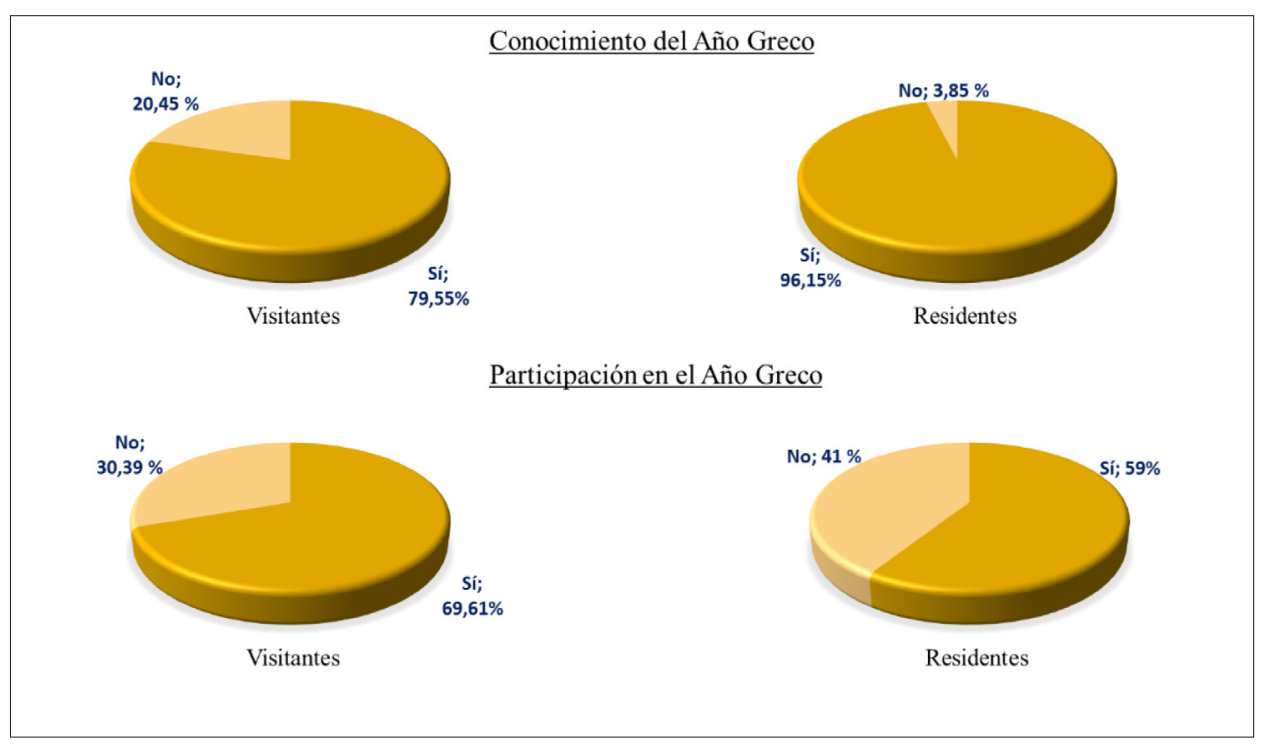

Fuente: Trabajo propio.

10 Además de la presencia en las redes sociales habituales. Por ejemplo, se desarrolló un canal oficial del Greco 2014 en YouTube (en red). 
La mayoría de los visitantes que acuden a la ciudad expresan que están realizando un viaje turístico cultural, el 90,6\%. Solo el 9,4\% restante señala otros motivos como visita familiar o por estudios. La pequeña muestra realizada provoca que este dato tenga una significación reducida. Sin embargo, al ser la mayoría de los encuestados turistas o excursionistas con una motivación cultural, esto permite indagar si fue el Año Greco el motivo principal para venir a Toledo o bien los valores patrimoniales de este destino turístico singular. Según la encuesta realizada por la Fundación El Greco 2014 (2015: 191) al público de las exposiciones principales del evento, el Greco fue el motivo primordial para el 57\% de los visitantes que llegaron a Toledo a lo largo del año, mientras que estimaban (sin citar la fuente) que antes solo era un 5\%. Realizando una encuesta lejos de los espacios principales del evento, el porcentaje de los visitantes que señalan al Greco como el porqué para escoger Toledo baja al 11,6\%. Las respuestas mayoritarias se relacionan con los valores cultures, patrimoniales e históricos generales del destino, un 79\%, como motivo principal de la visita. En el trabajo de Piva et al. (2017) el evento fue la razón más importante para ir al destino turístico. Pero en su investigación, Light $(1996,187)$ halla que el evento fue un incentivador adicional al objetivo principal de la visita turística cultural del patrimonio por sus valores históricos y estéticos. También en el ejemplo estudiado por Ruiz (2017:36) los que vienen específicamente al evento son una minoría. En el caso de Toledo, el evento cultural distintivo actúa sobre todo como un gran incentivo para el destino turístico. Y de manera secundaria, suma un porcentaje de visitantes que acuden expresamente por el acontecimiento.

Los visitantes que participaron en el Año Greco según la encuesta fueron el 69,61\%. De estos, el 61,11\% entraron en la exposición temporal del Museo de Santa Cruz. El $30,38 \%$ no fueron a ninguno de los Espacios Greco ni a la exposición principal durante su estancia a Toledo. Desciende el porcentaje de participación con respecto al del conocimiento del evento. No obstante, aumenta claramente en relación con el motivo principal de la visita. Como sucede en el estudio de Piva et al. (2017), aparecen encuestados que fueron al destino por otras razones y decidieron participar en el evento tras su llegada. El centenario es así un complemento importante y un incentivo para el destino cultural y patrimonial Toledo. De hecho, el grado de satisfacción del público de las exposiciones fue alto en un 97 \% (Fundación El Greco 2014, 2015: 187).

Con respecto a la comunidad anfitriona, la inmensa mayoría de los residentes toledanos encuestados, el 96,15\%, tienen conocimiento de la celebración del evento. El porcentaje es más elevado que entre los visitantes. Los residentes identificaron el 2014 con el Año Greco en Toledo. Por lo tanto, hay una relación clara entre la ciudad y la conmemoración en la percepción local. Los ciudadanos son conscientes de la celebración del evento distintivo. Hay una identidad cultural asociada a la ciudad a través de la figura del pintor cretense.

Light (1996: 186) descubre en su investigación sobre la asistencia de los eventos culturales en los sitios patrimoniales que estos atraen a una proporción mucho mayor de gente local y que los residentes expresan un claro interés en los mismos. Sin embargo, González y Morales (2017: 351) hallan que en Cataluña los eventos orientados al turismo tienen un menor impacto percibido sobre la asistencia de los residentes. En el caso de Toledo, la participación de los locales encuestados en los actos del Año Greco fue del 59\%. El 41\% restante no había visitado ninguno de los espacios relacionados con el Greco que había en la ciudad ni pensaba hacerlo. 
Este es un hallazgo fundamental de la investigación: la participación de la comunidad anfitriona desciende profundamente (59\%) con respecto al conocimiento del evento $(96,15 \%)$. Se cumple la máxima planteada por Boyko (2008) y Askins y Pain (2011) según la cual los eventos son focos de atracción de visitantes antes que acontecimientos culturales para los residentes.

\section{CONCLUSIONES}

El desarrollo del turismo cultural en los últimos años ha aumentado la competitividad entre los destinos. Los eventos distintivos tienen un alto valor turístico. Ciudades y territorios optan por la celebración de estos acontecimientos para aumentar el número de visitantes y los ingresos obtenidos a través del turismo, así como la imagen del destino y el sentido de comunidad. En este artículo se ha realizado un análisis post evento del IV Centenario de la muerte del Greco en 2014 en Toledo. Se trata de un evento distintivo realizado en un destino turístico cultural consolidado.

La primera pregunta de investigación que se planteaba era si ¿fue el Año Greco un impulso real de la actividad turística en Toledo? La respuesta obtenida es afirmativa. Supuso un punto de inflexión en el turismo del destino. Se preguntaba también si ¿aumentó realmente el número de visitantes? Las evidencias obtenidas demuestran que sí, la afluencia a la ciudad se incrementó significativamente por el evento. Por lo tanto, ¿generó ingresos? Nuevamente la respuesta es afirmativa tal y como demuestra la memoria de actividades del evento. Estamos ante un ejemplo de éxito de turismo de eventos en un destino turístico cultural. De hecho, el modelo ha sido seguido con posterioridad en otras ciudades españolas, como la celebración del Año Murillo en Sevilla.

También se pretendían examinar los resultados del evento a nivel sociocultural. Se planteaba en primer lugar si ¿los visitantes venían a Toledo por motivos culturales? Así sucede en su mayoría. Por lo tanto, surgía la cuestión de si ¿era el evento la razón por la cual habían optado por el destino? Y si, de hecho, ¿sabían que se celebraba? La encuesta demuestra que el grado de conocimiento previo de la existencia del Año Greco era amplio entre los visitantes, casi total en el caso de los domésticos. Sin embargo, los turistas y excursionistas encuestados relacionan el motivo principal de su visita con la cultura, el patrimonio y la historia del destino. No sería el evento la causa única ni la primordial de su llegada a Toledo. La conmemoración actúa como un impulso, extraordinario sí, para un destino con una imagen patrimonial previa muy definida que es el motivo principal de la visita. El Año Greco complementa esa imagen y logra aumentar la afluencia habitual de visitantes a la ciudad. Pero ¿los viajeros participan en las actividades culturales programadas por el evento? Sí, lo hacen en un $70 \%$ aproximadamente. Aun así, son diez puntos más los visitantes que saben del Año Greco (casi el 80\%) que los que participan.

Una cuestión que se planteaba como principal era si ¿los eventos culturales transcienden a la comunidad anfitriona? En la encuesta, más del 95\% de los residentes tenían conocimiento de la celebración del Año Greco en Toledo. Hay una identificación de la ciudad con el evento. Pero, ¿hay una participación activa de los locales en los actos programados? ¿Son los eventos culturales una motivación para que la comunidad anfitriona visite sus lugares patrimoniales? El resultado obtenido es que casi un $60 \%$ de los residentes encuestados visi- 
taron las exposiciones temporales y/o los Espacio Greco. Un 40\%, no. Es evidente que la diferencia dentro de la sociedad local entre los que conocen la celebración del evento y los que participan realmente en él es muy elevada en el estudio de caso realizado.

Los hallazgos de este estudio se ubican en el contexto de otras investigaciones de eventos en espacios patrimoniales. Este artículo ofrece puntos de discusión sobre el análisis de las ciudades históricas que utilizan cada vez más eventos culturales distintivos para mejorar su imagen, atraer visitantes e inversores y estimular el crecimiento económico a través del turismo. Se ha de considerar si los eventos culturales distintivos han de implicar activamente a la comunidad anfitriona. Sus organizadores deben plantearse si los resultados se detienen en el turismo y en la identidad cultural local, o si también se han de cumplir objetivos culturales, educativos y de uso social del patrimonio mediante la participación activa de una mayoría sustancial de residentes.

\section{BIBLIOGRAFÍA}

ABC (2014): «Exposición «El Griego de Toledo». Cambios en el sistema de visita ante la masiva afluencias», 30/3/2014. Disponible en <http://www.abc.es/comunidad-castillalamancha/20140330/abcp-exposicion-griego-toledo-cambios-20140330.html >. [12 de febrero de 2018].

AGENCIA EFE (2015): «La Fundación El Greco cierra y pasa su legado a la Real Fundación de Toledo», 25/11/2015. Disponible en <https://www.efe.com/efe/espana/cultura/ la-fundacion-el-greco-cierra-y-pasa-su-legado-a-real-de-toledo/10005-2773595>. [21 de febrero de 2018].

AMARA, D. (2017): «Events tourism: A potential to build a tourist destination branding: the case of cultural events in Egypt», International Journal of Heritage, Tourism and Hospitality, vol. 11 (2). Disponible en < http://journals.fayoum.edu.eg/index.php/ Tourism/article/view/375>. [8 de febrero de 2018].

ASHWORTH, G. J. (1993): «Culture and tourism, conflict or symbiosis in Europe?», en POMPL, W. y LAVERY, P. (Eds.): Tourism in Europe. Londres, Mansell, pp. 13-35.

ASHWORTH, G.J. y TUNBRIDGE, J.E. (2000): The touristic-historic city. Retrospect and the prospect of managing the heritage city. Oxford, Pergamon.

ASKINS, K. y PAIN, R. (2011): «Contact zones: participation, materiality, and the messiness of interaction», Environment and planning D: Society and Space, vol. 29 (5), pp. 803-821.

AYUNTAMIENTO DE ORIHUELA (en red): 75 aniversario de la muerte de Miguel Hernández. Disponible en <http://75mhorihuela2017.orihuela.es/>. [10 de febrero de 2018].

AYUNTAMIENTO DE SEVILLA (en red): Murillo y Sevilla. Disponible en <http://www. murilloysevilla.org/>. [10 de febrero de 2018].

AYUNTAMIENTO DE TOLEDO (2017): Huellas de Teresa de Jesús, folleto. Copia disponible <https://www.dropbox.com/s/aeuqpka69oe1waw/Huellas_Teresa_ Jes\%C3\%BAs_Toledo.pdf?dl=0>.

BABBIE, E. R. (2015): The practice of social research (14 ${ }^{\mathrm{a}}$ edición). Belmont, Wadsworth. 
BACKMAN, K. (2018): «Event management research: The focus today and in the future», Tourism Management Perspectives, vol. 25, pp. 169-171.

BACKMAN, K., HSU, Ch. y BACKMAN, S. (2011): «Tao Residents' Perceptions of social and cultural impacts of tourism in Lan-Yu, Taiwan», Event Management, vol. 15 (2), pp. 121-136.

BARRERA FERNÁNDEZ, D. (2013): «La tematización de la ciudad en torno a un personaje. El caso de Picasso y Málaga», Agir. Revista interdisciplinar de Ciencias Sociales y Humanas, vol. 1 (5), pp. 8-20.

BARRERA FERNÁNDEZ, D. y HERNÁNDEZ ESCAMPA, M. (2017): «Events and placemaking: the case of the Festival Internacional Cervantino in Guanajuato, México», International Journal of Event and Festival Management, vol. 8 (1), pp. 24-38.

BAXTER, P. y JACK, S. (2008): «Qualitative case study methodology: Study design and implementation for novice researchers», The Qualitative Report, vol. 13 (4), pp. 544-559.

BEDATE, A., HERRERO, L.C. y SANZ, J.A. (2004): «Economic valuation of the cultural heritage: application to four case studies in Spain», Journal of Culture Heritage, vol. 5 (1), pp. 101-111.

BEEK, R.M. y GO, F. (2017): «Legacy of hallmark events: cross-cultural analysis among emerging destinations», en LITTLE, E.; GO, F. y POON, T. S. C.: Global innovation and entrepreneurship. Springer, eBook.

BOYKO, C.T. (2008): «Are you being served? The impacts of a tourist hallmark event on the place meanings of residents», Event Management, vol. 11 (4), pp. 161-177.

BOYLE, M. (1997): «Civic boosterism in the politics of local economic development - 'institutional positions' and 'strategic orientations' in the consumption of hallmark events», Environment and Planning A, vol. 29 (11), pp. 1975-1997.

BRANDIS GARCÍA, D. y DEL RÍO LAFUENTE, M.I. (1998): «Turismo y medio ambiente urbano. Las experiencias de Ávila, Toledo y Salamanca», en GARCÍA, J. y TROITIÑO, M.A.: Vivir las ciudades históricas: recuperación integrada y dinámica funcional. Cuenca, Fundación La Caixa/UCLM, pp. 155-182.

BRITTON, S. G. (1991): «Tourism, capital and place: towards a critical geography of tourism», Environment and Planning D: Society and Space, vol. 9 (4), pp. 451-478.

BURGAN, B. y MULES, T. (2001): «Reconciling cost-benefit and economic impact assessment for event tourism», Tourims Economics, vol. 7 (4), pp. 321-330.

CAVAILLÈS, C., LAURENT, M., MAURIN, S. y SÁNCHEZ HERNÁNDEZ, J. L. (2016): «Los turistas en el centro histórico de Salamanca: tránsito, percepción y (des) conocimiento», Cuadernos de Turismo, n 37, pp. 37-67.

CENTRO NACIONAL DE INFORMACIÓN GEOGRÁFICA (CNIG) (en red): Centro de descargas. Disponible en <http://centrodedescargas.cnig.es/CentroDescargas/index. jsp>. [10 de febrero de 2018].

COMISIÓN EUROPEA (2016): Preferences or Europeans towards tourism. Disponible en: $<$ https://data.europa.eu/euodp/es/data/dataset/S2065_432_ENG>. [23 de mayo de 2017].

CORDENTE RODRÍGUEZ, M.; ESTEBAN TALAYA, A.; MONDÉJAR JIMÉNEZ, J. A. y ANDRÉS MARTÍNEZ, M. E. (2011): «Medición de motivaciones del turismo cultural en ciudades Patrimonio de la Humanidad», Revista de Análisis Turístico, ${ }^{\circ}$ 12 , pp. $80-85$. 
CUDNY, W. (2016): Festivalisation of urban spaces. Factors, processes and effects. Cham, Springer.

CHOAY, F. (2007): La alegoría del patrimonio. Barcelona, Gustavo Gili.

CHAMBERS, E. (Ed.) (1997): Tourism and culture: An applied perspective, Albany, State University of New York Press.

CHIRIELEISON, C. y SCRUCCA, L. (2017): «Event sustainability and transportation policy: A model-based cluster analysis for a cross-comparison of hallmark events», Tourism Management Perspectives, vol. 24, pp. 72-85.

DE LA CALLE VAQUERO, M. (2002): La ciudad histórica como destino turístico. Barcelona, Ariel.

DE LA CALLE VAQUERO, M. (2013): «Turismo cultural y destinos turísticos», en PULIDO, J. I. (Coord.): Turismo cultural. Madrid, Síntesis, pp. 203-234.

DE LA CALLE VAQUERO, M. y GARCÍA HERNÁNDEZ, M. (1998): «Ciudades históricas: patrimonio cultural y recurso turístico», Ería, no 47, pp. 249-266.

DE LA CALLE VAQUERO, M. y GARCÍA HERNÁNDEZ, M. (2016): «Políticas locales de turismo en ciudades históricas españolas. Génesis, evolución y situación actual», Pasos, Revista de Turismo y Patrimonio Cultural, vol. 14, n 3, pp. 691-704.

DEVESA FERNÁNDEZ, M., HERRERO PRIETO, L.C. y SANZ LARA, J.A. (2009): «Análisis económico de la demanda de un festival cultural», Estudios de Economía Aplicada, vol. 27 (1), pp. 137-158.

DÍAZ SÁNCHEZ, E., ESTEBAN TALAYA, A., MARTÍN-CONSUEGRA NAVARRO, D. y MOLINA COLLADO, A. (2007): «Segmentación de la demanda turística: un análisis aplicado a un destino de turismo cultural», Revista de Análisis Turístico, n 4, pp. 36-48.

ESCUDERO GÓMEZ, L.A. (2018): «The realities and issues of a major cultural tourist destination in Spain, Toledo». Pasos, Revista de Turismo y Patrimonio Cultural, vol. 16 (3), pp. 617-636.

FESSLER VAZ, L. y BERENSTEIN JACQUES, P. (2006): «Contemporary urban spectacularisation», en MONCLÚS, J. y GUÀRDIA, M. (Eds.): Culture, Urbanism and Planning. Routledge, eBook.

FORMICA, S. (1998): «The development of festivals and special events studies», Festival Management and Event Tourism, vol. 5 (3), pp. 131-137.

FUNDACIÓN EL GRECO 2014 (2014): Programa oficial, folleto. Copia disponible en <https://www.dropbox.com/s/g7z8ti70u28nb3i/Programa\%20El\%20Greco\% 202014. pdf?dl=0>.

FUNDACIÓN EL GRECO 2014 (2015): Memoria de actividades. El Greco 2014 IV Centenario. Toledo, Fundación El Greco 2014.

GARCÍA, A. (2014): «El año en el que El Greco batió todos los récords», Diario El País, 18/4/2014. Disponible en < https://elpais.com/cultura/2014/12/18/actualidad/1418932710_777201.html>. [9 de febrero de 2018].

GARCÍA ÁLVAREZ, J. (2007): «Paisajes nacionales, turismo y políticas de memoria: Toledo (1900-1950)», Ería, no 73-74, pp. 193-212.

GARCÍA HERNÁNDEZ, M. y DE LA CALLE VAQUERO, M. (2012): «Capacidad de carga en grandes recursos turísticos-culturales», Anales de Geografía de la Universidad Complutense, vol. 32 (2), pp. 253-274. 
GARCÍA MARCHANTE, J.S. (2011): «Cuenca: un destino turístico consolidado», Cuadernos de Turismo, $\mathrm{n}^{\circ} 27$, pp. 403-418

GARCÍA MARTÍN, J.A. (2013): «Market segmentation based on time use: an empirical analysis in the historic city of Toledo, Spain», Current Issues in Tourism, vol. 19 (2), pp. 155-173.

GARCÍA MARTÍNEZ, C. (2011): «La imagen en el turismo urbano: revisitando el Toledo romántico», Cuadernos de Turismo, n 27, pp. 437-453.

GARROD, B. y FYALL, A. (2001): «Heritage tourism: A question of definition», Annals of Tourism Research, vol. 28 (4), pp. 1049-1052

GETZ, D. (1989): «Special events: Defining the product», Tourism Management, vol. 10 (2), pp. 135-137.

GETZ, D. (1991): Festivals, special events, and tourism. Nueva York, Van Nostrand Rheinhold.

GETZ, D. (1997): Event management and event tourism ( $1^{\text {a }}$ edición). Nueva York, Cognizant.

GETZ, D. (2005): Event management and event tourism (2 $2^{\mathrm{a}}$ edición). Nueva York, Cognizant.

GETZ, D. (2007): Event studies: Theory, research and policy for planned events (1 edición). Burlington, Elsevier.

GETZ, D. (2008): «Event tourism, definition, evolution and research», Tourism Management, vol. 29 (3), pp. 403-428.

GETZ, D. (2013): Event tourism: Concepts, international case studies and research. Nueva York, Cognizant.

GETZ, D. y PAGE, S.J. (2016a): Event studies: Theory, research and policy for planned events ( $3^{\text {a }}$ edición). Londres, Routledge.

GETZ, D. y PAGE, S.J. (2016b): «Progress and prospects for event tourism research», Tourism Managment, vol. 52, pp. 593-631.

GONZÁLEZ REVERTÉ, F. y MORALES PÉREZ, S. (2009): Ciudades efímeras: transformando el turismo urbano a través de la producción de eventos. Barcelona, UOC.

GONZÁLEZ REVERTÉ, F. y MORALES PÉREZ, S. (2017): «El impacto cultural y social de los eventos celebrados en destinos turísticos. La percepción desde el punto de vista de los organizadores», Cuadernos de Turismo, n ${ }^{\circ} 40$, pp. 339-362.

GRATTON, C. (2005): «The economic context of Cultural Tourism», en RICHARDS, G. (Ed.): Cultural Tourism in Europe. Association for Tourism and Leisure Education, pp.55-66. Disponible en: <http://www.tram-research.com/cultural_tourism_in_europe. pdf>. [20 de abril de 2017].

HALL, M. (1989): «The definition and analysis of hallmark tourist events», GeoJournal, vol. 19 (3), pp. 263-268.

HALL, M. (1992): Hallmark tourist events: Impacts, management and planning. Londros, Belhaven.

HERBERT, D. T. (Ed.) (1995): Heritage, Tourism and Society. Londres, Mansell.

HERRERO PRIETO, L. C. y GÓMEZ VEGA, M. (2017): «Cultural resources as a factor in cultural tourism attraction: Technical efficiency estimation or regional destinations in Spain», Tourism Economics, vol. 23 (2), pp. 260-280. 
HOLLINSHEAD, K., KUON, V. y ALAJMI, V. (2015): «Events in the liquid modern world: the call for fluid acumen in the presentation of peoples, places, pasts and presents», en MOUFAKKIR, O. y PERNECKY, T. (Ed.S): Ideological, social and cultural aspects of events. CABI, pp. 12-27.

INSTITUTO NACIONAL DE ESTADÍSTICA(INE) (en red): Encuesta de ocupación hotelera. Disponible en http://www.ine.es/dynt3/inebase/es/index.htm?padre=238\&dh=1. [2 de noviembre de 2018].

JACKSON, L. (2008): «Residents' perceptions of the impacts of special event tourism», Journal of Place Management and Development, vol. 1 (3), pp. 240-55.

JAGO, J. y SHAW, R. (1998): «Special events: A conceptual and definitional framework», Festival Management and Event Tourism, vol. 5 (1), pp. 21-32.

JANSEN-VERBEKE, M. y LIEVOIS, E. (1999): «Analysing heritage resources for urban tourism in European cities», en PEARCE, D. G. y BUTLER, R. W. (Eds.): Contemporary Issues in Tourism Development. Nueva York, Routledge, pp. 81-107.

LAGUNA GARCÍA, M. (2005): «La celebración de eventos culturales como atractivo turístico en las ciudades históricas: análisis del impacto económico y turístico», Estudios Turísticos, $\mathrm{n}^{\circ}$ 166, pp. 65-97.

LANDFORD, C. (2007): «Managing for sustainable tourism: a review of six cultural World Heritage Sites», Journal of Sustainable Tourism, vol. 17 (1), pp. 53-70.

LARA DE VICENTE, F. y LÓPEZ-GUZMAN GUZMAN, T. J. (2004): «El turismo como motor de desarrollo económico en ciudades patrimonio de la humanidad», Pasos. Revista de Turismo y Patrimonio Cultural, vol. 2 (2), pp. 243-256.

LEIPER, N. (1990): «Tourist attraction systems», Annals of Tourism Research, vol. 17 (3), pp. 367-384. LIGHT, D. (1996): «Characteristics of the audience for 'events' at a heritage site», Tourism Management, vol. 17 (3), pp. 183-190.

LITTRELL, M. A.; ANDERSON, L. F. y BROWN, P. J. (1993): «What makes a craft souvenir authentic?», Annals of Tourism Research, vol. 20 (1), pp. 197-215.

LÓPEZ-GUZMÁN GUZMÁN, T.J., PÉREZ GÁLVEZ, J.C. y MUÑOZ FERNÁNDEZ, G.A. (2018): «Satisfaction, motivation, loyalty and segmentation of tourists in World Heritage Cities», Pasos. Revista de Turismo y Patrimonio Cultural, vol. 16 (1), pp. 73-86.

LÓPEZ LÓPEZ, A. (2005) «Desarrollo sostenible: medio ambiente y turismo en las ciudades históricas: el caso de Toledo», Revista Observatorio Ambiental, nº 8, pp. 331-344.

LOVELL, J. y BULL, C. (2017): Authentic and inauthentic places in tourism: From heritage site to theme parks. Abingdon, Routledge.

LUNDBERG, E. (Ed.) (2017): The Value of Events. Londres, Routledge.

MAIR, J. y WHTIFORD, M. (2013): «An exploration of events research: event topics, themes and emerging trends», International Journal of Event and Festival Management, vol. 4 (1), pp. 6-30.

MARTÍN PORTUGUÉS, I. (2017): Difusión del valor cultural en las ciudades Patrimonio Mundial de la Península Ibérica. Estudio pormenorizado del caso de Toledo, Tesis Doctoral. Sevilla, Universidad de Sevilla. Disponible en <https://idus.us.es/xmlui/ handle/11441/63982>. [29 de agosto de 2017]. 
MARTÍNEZ GIL, F. (2007): La invención de Toledo. Imágenes históricas de una identidad urbana. Ciudad Real, Almud.

MARTÍNEZ SALA, A.M. y CAMPILLO ALHAMA, C. (2018): «Los eventos, herramienta en las estrategias de comunicación de marcas turísticas: de la linealidad a la transmedialidad», Revista Mediterránea de Comunicación, vol. 9 (1), pp. 291-312

MARTOS MOLINA, M. (2013): «El papel del turismo de eventos en el desarrollo urbano. El caso de Expo Zaragoza», Pasos Revista de Turismo y Patrimonio Cultural, vol. 11 (1), pp. 57-71.

MARTOS MOLINA, M. (2016): Herramientas para la gestión turística del patrimonio cultural. Manual para gestores culturales. Gijón, Ediciones Trea.

MEHMETOGLU, M. y ENGEN, M. (2011): «Pine and Gilmore's concept of experience economy and its dimensions: An empirical examination in tourism», Journal of Quality Assurance in Hospitality \& Tourism, vol. 12 (4), pp. 237-255.

MÍNGUEZ GARCÍA, M.C. (2013): «La actividad cultural en los destinos turísticos patrimoniales españoles: el caso de Ávila, Segovia y Toledo», Revista América Patrimonio, $\mathrm{n}^{\mathrm{o}} 4$, pp. 13-25.

MOSSBERG, L. (2000): «Effects of events on destination image», en MOSSBERG, L. (Ed.): Evaluation of events: Scandinavian experiences. Nueva York, Cognizant, pp. 30-46.

MUÑIZ MARTÍNEZ, N. y CERVANTES BLANCO, M. (2010): «Marketing de ciudades y "place branding"», Revista Pecunia: Revista de la Facultad de Ciencias Económicas y Empresariales, $\mathrm{n}^{\circ}$ extra 1, pp.123-149.

MURILLO VIU, J., ROMANÍ FERNÁNDEZ, J. y SUÑIRACH CARALT, J. (2008): «The impact of heritage tourism on an urban economy: The case of Granada and the Alhambra», Tourism Economics, vol. 14 (2), pp. 361-376.

NORDVALL, A. y HELDT, T. (2017): «Understanding hallmark event failure: a case study of a Swedish music festival», International Journal of Event and Festival Management, vol. 8 (2), pp. 172-185.

NOVELLO, S., MARTÍNEZ ROGET, F.; MURIAS FERNÁNDEZ, P. y MIGUEL DOMÍNGUEZ, J.C. (Eds.) (2014): Xacobeo. De un recurso a un evento turístico global. Santiago de Compostela, Andavidara.

OKLOBDZIJA, S. (2015): «The role of events in tourism development», Bizinfo Blace, vol. 6 (2), pp. 83-97.

OOM DO VALLE, P. O., MENDES, J. y GUERREIRO, M. (2012): «Residents' participation in events, events image, and destination image: a correspondence analysis», Journal of Travel and Tourism Marketing, vol. 29 (7), pp. 647-664.

PILLET CAPDEPÓN, F. (2017): «Los espacios del turismo», en PILLET, F.: Geoliteratura. Paisaje literario y turismo. Madrid, Síntesis, pp. 135-145.

PINE, B.J. y GILMORE, J. H. (1999): The experience economy. Boston, Harvard Business School Press.

PIVA, E.; CERRUTI, S., PRATS, L. y RAJ, R. (2017): «Enhancing brand image through events and cultural festivals: The perspective of the Stresa Festival's visitors», Almatourism, $\mathrm{n}^{\mathrm{0}} 15$, pp. 99-116. 
PRENTICE, R. C. (1993): Tourism and Heritage Attractions. Londres, Routledge.

PULIDO FERNÁNDEZ, J.I. (Coord.) (2013): Turismo cultural. Madrid, Síntesis.

PULIDO FERNÁNDEZ, J.I. y RUIZ LANUZA, A. (2017): «Propuesta para una agenda de investigación de los impactos del turismo en los destinos Patrimonio de la Humanidad», Boletín de la Asociación de Geógrafos Españoles, ${ }^{\circ}$ 73, pp. 389-411.

RAM, Y, BJÖRK, P. y WEIDENFELD, A. (2016): «Authenticity and place attachment of major visitor attractions», Tourism Management, vol. 52, pp. 110-122.

REAL FUNDACIÓN DE TOLEDO (en red): «La Fundación». Disponible en <http:// www.realfundaciontoledo.es/html/index.html >. [1 de febrero de 2018].

RECUERO VIRTO, N., BLASCO LÓPEZ, F. y GARCÍA DE MADARIAGA MIRANDA, J. (2016): Marketing del turismo cultural. Madrid, ESIC.

RICHARDS, G. (1993): «Cultural Tourism in Europe», en COOPER, C.P. y LOCKWOOD, A. (Eds.): Progress in tourism, recreation and hospitality management volume 5. Chichester, Wiley, pp. 99-115.

RICHARDS, G. (Ed.) (1996): Cultural Tourism in Europe. Wallingford, UC CAB International.

RICHARDS, G. (2001): «El desarrollo del turismo cultural en Europa», Estudios Turísticos, $\mathrm{n}^{\mathrm{o}} 150$, pp. 3-13.

RICHARDS, G. (Ed.) (2005): Cultural Tourism in Europe. Association for Tourism and Leisure Education. Disponible en: <http://www.tram-research.com/cultural_tourism_ in_europe.PDF>. [20 de abril de 2017].

RICHARDS, G. (2007): ATLAS Cultural Tourism Survey. Summary report 2007. Disponible en: <http://www.tram-research.com/atlas/ATLAS\%20Cultural\%20Tourism\%20 Survey\%202007.PDF>. [18 de febrero de 2017].

RICHARDS, G. (2017): «Measuring event experiences: An international view», en RICHARDS, G. y RUIZ, A. (Coords.): Experiencias turísticas de festivales y eventos. Tenerife, Pasos, Revista de Turismo y Patrimonio Cultural, pp. 11-28.

RICHARDS, G. y BONINK, C. (1995): «Marketing cultural tourism in Europe», Journal of Vacation Marketing, vol. 1 (2), pp. 173-180.

RICHARDS, G. y MUNSTERS, W. (Eds.) (2010): Cultural Tourism research methods. Wallingford, CAB International.

RICHARDS, G. y PALMER, R. (2010): Eventful Cities: Cultural Management and Urban Revitalisation. Londres, Routledge.

RICHARDS, G. y RUIZ LANUZA, A. (2017): «Introducción», en RICHARDS, G. y RUIZ, A. (Coords.): Experiencias turísticas de festivales y eventos. Tenerife, Pasos, Revista de Turismo y Patrimonio Cultural, pp. 5-10.

RICHARDS, G. y WILSON, J. (2004): «The impact of cultural events on city image: Rotterdam, cultural capital of Europe 2001», Urban Studies, vol. 41 (10), pp. 1931-1951 _ <

RICO JEREZ, M., PARRA MEROÑO, M.C. y BELTRÁN BUENO, M.A. (2018): «Las estrategias de marketing de las ciudades patrimonio como destinos turísticos: el caso de Toledo $30^{\circ}$ aniversario», International Journal of Scientific Management and Tourism, vol. 4 (1), pp. 149-166 
RITCHIE, BRENT J.R. (1984): «Assessing the impact of hallmark events: Conceptual and research issues», Journal of Travel Research, vol. 23 (1), pp. 2-11.

RITCHIE, BRENT J. R. y BELIVEAU, Donald (1974): «Hallmark events: An evaluation of a strategic response to seasonality in the travel market», Journal of Travel Research, vol. 13 (2), pp. 14-20.

RODRÍGUEZ CHUMILLAS, G. (2015): «Los centenarios: eventos dinamizadores de la cultura, el arte y a la industria del turismo en Castilla-La Mancha», en RODRÍGUEZ CHUMILLAS, I. et al. (Dirs.): Entre pliegues del turismo. Desde el territorio y las representaciones en España y México. Madrid, Universidad Autónoma de Madrid, pp. 69-80.

ROMERO GALLARDO, S. I. y ALVARADO SIZZO, I. (2017): «La Noche de Muertos en Janitzio: Percepción de residentes y visitantes en torno a una festividad masiva», en RICHARDS, G. y RUIZ, A. (Coords.): Experiencias turísticas de festivales y eventos. Tenerife, Pasos, Revista de Turismo y Patrimonio Cultural, pp. 53-72.

ROSLOW, S.; NICHOLLS, J.A.F. y LASKEY, H. A. (1992): «Hallmark events and measures of reach and audience characteristics», Journal of Advertising Research, vol. 32 (4), pp. 53-59.

RUIZ-AYÚCAR ALONSO, M. A. (2002): «Toledo y el turismo. El Plan de Excelencia Turística de Toledo», en CAMPOS, M.L. (Coord.): El turismo en Castilla-La Mancha: análisis y prospectiva. Cuenca, Universidad de Castilla-La Mancha, pp. 155-174.

RUIZ LANUZA, A. (2017): «Dinámica de la experiencia turística y cultural del Festival Internacional Cervantino», en RICHARDS, G. y RUIZ, A. (Coords.): Experiencias turísticas de festivales y eventos. Tenerife, Pasos, Revista de Turismo y Patrimonio Cultural, pp. 29-52.

SALGUERO MONTAÑO, O. (2016): «Granada(s), un tronco, muchas ramas», en RODRÍGUEZ, J. y SALGUERO, O. (Coords.): Cartografía de la ciudad capitalista. Transformación urbana y conflicto social en el Estado español. Madrid, Traficantes de Sueños, pp. 249-274.

SALOM CARRASCO, J. y PITARCH GARRIDO, M.D. (2017): «Análisis del impacto en el turismo de la estrategia de desarrollo urbano basada en megaproyectos. El caso de la ciudad de Valencia», Cuadernos de Turismo, n ${ }^{\circ}$ 40, pp. 573598.

SÁNCHEZ-CHIQUITO DE LA ROSA, S. (2010): «El patrimonio desconocido descubre otro Toledo. Un modelo de gestión del patrimonio arqueológico», en AA.VV.: Simposium Internacional soluciones sostenibles para las ciudades patrimonio mundial. Valladolid, Fundación del Patrimonio Histórico de Castilla y León, pp. 193-204.

SÁNCHEZ LLORENS, M. y GUITART VILCHES, M. (2017): «Espacios-imantados y manifestaciones culturales. El misterio del turismo de lo cotidiano», en Planur-e, $\mathrm{n}^{\circ}$ 9. Disponible en: <http://www.planur-e.es/articulos/ver/espacios-imantados-y-manifestaciones-culturales-el-misterio-del-turismo-de-lo-cotidiano->. [15 de diciembre de 2017].

SHARPLEY, R y STONE, P.R. (2012): «Socio-cultural impacts of events», en PAGE, J. y CORNELL, J. (Eds.): The Routledge Handbook of Events. Londres, Routledge, pp. 347-361. 
SHEEHAN, Lorn; VARGAS-SÁNCHEZ, Alfonso; PRESENZA, Angelo y ABBATE, Tindara (2016): «The use of intelligence in tourism destination management: An emerging role for DMOs», International Journal of Tourism Research, vol. 18 (6), pp. 549-557.

SILVA PÉREZ, R. y FERNÁNDEZ SALINAS, V. (2008): «El patrimonio y el territorio como activos para el desarrollo desde la perspectiva del ocio y del turismo», Investigaciones Geográficas, nº 46, pp. 69-88.

SMITH, A. (2012): Events and urban regeneration. The strategic use of events to revitalise cities. Londres, Routledge.

SYME, G., SHAW, B.; FENTON, D. y MUELLER, W. (Eds.) (1989): The planning and evaluation of hallmark events. Aldershot, Gower.

STOKES, R. (2004): «A framework for the analysis of events tourism knowledge networks», Journal of Hospitality and Tourism Management, vol. 11 (2), pp. 108-13.

SU, M.M. y WALL, G. (2013): «Community involvement at Great Wall World Heritage sites, Beijing, China», Current Issues in Tourism, vol. 18 (2), pp. 137-157.

THROSBY, D. (2011): «Cultural capital», en Towse, R. (Ed.): A handbook of cultural economics ( $2^{\text {a }}$ edición). Cheltenham, Edward Elgar, pp. 142-146.

TIMOTHY, D.J. (2011): Cultural heritage and tourism: an introduction. Bristol, Channel View Publications.

TIMOTHY, D.J. y BOYD, S.W. (2003): Heritage Tourism. Harlow, Prentice Hall.

TIMOTHY, D.J. y BOYD, S.W. (2006): «Heritage Tourism in the 21st Century: valued traditions and new perspectives», Journal of Heritage Tourism, vol. 1 (1), pp. 1-16.

TODD, L., LEASK, A. y ENSOR, J. (2017): «Understanding primary stakeholders' multiple roles in hallmark event tourism management», Tourism Management, vol. 59, pp. 494-509.

TRANQUILLI, A. (2013): Urban regeneration, cultural events and intercultural communication. A case study of Mantua, candidate city for European Capital of Culture 2019». Tesis de grado, Università Degli Studi di Padova.

TROITIÑO TORRALBA, L. (2005): «La oferta patrimonial y cultural de la ciudad de Toledo y su funcionalidad turística», en ORTEGA, E.; GONZÁLEZ, L. y PÉREZ DEL CAMPO, E. (Eds.): VIII Forum Internacional sobre las Ciencias, las Técnicas y el Arte Aplicadas al Marketing. Academia y Profesión. Madrid, Universidad Complutense de Madrid, pp. 415-434.

TROITIÑO TORRALBA, L. (2010): «La funcionalidad turística de los recursos monumentales de las ciudades Patrimonio de la Humanidad: Ávila, Cuenca, Segovia y Toledo», en TROITIÑO, M.A. et al. (Coords.): Dinámicas funcionales del turismo y sus impactos en las ciudades Patrimonio de la Humanidad: Ávila, Cuenca, Segovia y Toledo. Guanajuato, Universidad de Guanajuato, pp. 106-121.

TROITIÑO VINUESA, M.A. (1997): «Turismo cultural. La ciudad de Toledo», en AA. VV.: La actividad turística española en 1996. Madrid, AECIT, pp. 507-513.

TROITIÑO VINUESA, M.A.; BRANDIS, D.; DEL RÍO, I.; DE LA CALLE, M.; GUTIÉRREZ, J.; LOBO, P. y MARTIN, F. (1998): «Toledo: problemática e implicaciones urbanas del turismo», Ería, no 47, pp. 299-325.

TROITIÑO VINUESA, M.A.; GARCÍA HERNÁNDEZ, M. y DE LA CALLE VAQUERO, M. (2000): «Reorganising accessibility by car: The case of Toledo», en MARENTE, 
M. y MINGHETTI, V. (Eds.): Visitor and Mobility Mangement in Tourism Destinations. Venecia, CISET/Universitá Ca’Foscari di Venezia, pp. 93-107.

TROITIÑO VINUESA, M.A.; GARCÍA HERNÁNDEZ, M. y DE LA CALLE VAQUERO, M. (2003): «Los visitantes de las ciudades históricas españolas: caracteres generales y rasgos específicos inducidos por la celebración de eventos turísticos-culturales», en ORTEGA, E.: Investigación y estrategias turísticas. Madrid, Thomson, pp. 37-64. TROITIÑO VINUESA, M.A. y TROITIÑO TORRALBA, L. (2009): «Toledo: características y problemáticas de un destino patrimonial», en TROITIÑO, M.A. (Ed.): Ciudades Patrimonio de la Humanidad. Patrimonio, turismo y recuperación urbana. Sevilla, Universidad Internacional de Andalucía, pp. 216-251.

TROITIÑO VINUESA, M.A. y TROITIÑO TORRALBA, L. (2010): «Patrimonio y turismo: una complementariedad necesaria en un contexto de uso responsable del patrimonio y cualificación de la visita», Revista Patrimonio Cultural de España, ${ }^{\circ}$ 3, pp. 89-108.

TRONCOSO, C.A. y ALMIRÓN, A.V. (2005): «Turismo y patrimonio. Hacia una relectura de sus relaciones», Aportes y Transferencias, vol. 9 (1), pp. 56-74.

UNIVERSIDAD COMPLUTENSE (en red): «El Greco 2014. Estudio sobre la capacidad de acogida de visitantes de los Espacios Greco, organización de la visita y recualificación del destino patrimonial». Disponible en < https://www.ucm.es/capacidadcargaturistica/ el-greco-2014-estudio-sobre-la-capacidad-de-acogida-de-visitantes-de-los-espaciosgreco,-organizacion-de-la-visita-y-recualificacion-del-destino-patrimonial-1>. [2 de febrero de 2018]

VÁZQUEZ VARELA, C. y MARTÍNEZ NAVARRO, J.M. (2016): «High-speed railway and tourism: Is there an impact on intermediate cities? Evidence from two case studies in Castilla-La Mancha (Sapin)», Journal of Urban and Regional Analysis, vol. 8 (2), pp. 133-158.

VELASCO GONZÁLEZ, M. (2016): «Entre el poder y la racionalidad: gobierno del turismo, política turística, planificación turística y gestión pública del turismo», Pasos, Revista de Turismo y Patrimonio Cultural, vol. 14, nº 3, pp. 577-594.

WAITT, G. (2000): «Consuming heritage: Perceived historical authenticity», Annals of Tourism Research, vol. 27 (4), pp. 835-862.

WEAVER, D. B. y LAWTON, L. J. (2013): «Residents perception of a contentious tourism event», Tourism Management, vol. 37, pp. 165-175.

YIN, R.K. (2003): Case study research: Design and methods ( $3^{\text {a }}$ edición). Thousand Oaks, Sage.

YOUTUBE (en red): El Greco 2014. Disponible en <https://www.youtube.com/channel/ UCB-fRZGIA1mJf2V89zbGv-g/feed>. [17 de febrero de 2018].

ZÁRATE MARTÍN, M.A. (2000): «Toledo, Ciudad Patrimonio de la Humanidad», Boletín de la Real Sociedad Geográfica, vol. CXXXVI, pp. 137-184.

ZÁRATE MARTÍN, M.A. (2008): «Estrategias de dinamización turística en una ciudad Patrimonio de la Humanidad, Toledo», en TROITIÑO, M.A.; GARCÍA MARCHANTE, J.S. y GARCÍA, M. (Coords.): Destinos turísticos: viejos problemas, ¿nuevas soluciones? Cuenca, Universidad de Castilla-La Mancha, pp. 355-368. 
ZÁRATE MARTÍN, M.A. (2016): «Los paisajes de Toledo, bajo las dinámicas urbanas y las oportunidades para el desarrollo local», en ZÁRATE, M. A. (Dir.): Paisajes culturales a través de casos en España y América. Madrid, UNED, pp. 23-76.

ZEPPEL, H. y HALL, C.M. (1991): «Selling art and history. Cultural heritage and tourism», Journal of Tourism Studies, vol. 2 (1), pp. 29-45.

ZEPPEL, H. y HALL, C.M. (1992): «Arts and heritage tourism», en WEILER, B. y HALL, C. M. (Eds.): Special interest tourism. Londres, Belhaven Press, pp. 45-60.

ZUKIN, S. (1991): Landscapes of power: from Detroit to Disney World. Berkeley, University of California Press. 